\title{
Nanostructure designs for effective solar-to-hydrogen conversion
}

\author{
Shaohua Shen and Samuel S. Mao* \\ Lawrence Berkeley National Laboratory, Department of \\ Mechanical Engineering, University of California \\ at Berkeley, Berkeley, CA 94720, USA, \\ e-mail: ssmao@lbl.gov \\ *Corresponding author
}

\begin{abstract}
Conversion of energy from photons in sunlight to hydrogen through solar splitting of water is an important technology. The rising significance of producing hydrogen from solar light via water splitting has motivated a surge of developing semiconductor solar-active nanostructures as photocatalysts and photoelectrodes. Traditional strategies have been developed to enhance solar light absorption (e.g., ion doping, solid solution, narrow-band-gap semiconductor or dye sensitization) and improve charge separation/transport to prompt surface reaction kinetics (e.g., semiconductor combination, co-catalyst loading, nanostructure design) for better utilizing solar energy. However, the solar-to-hydrogen efficiency is still limited. This article provides an overview of recently demonstrated novel concepts of nanostructure designs for efficient solar hydrogen conversion, which include surface engineering, novel nanostructured heterojunctions, and photonic crystals. Those first results outlined in the main text encouragingly point out the prominence and promise of these new concepts principled for designing high-efficiency electronic and photonic nanostructures that could serve for sustainable solar hydrogen production.
\end{abstract}

Keywords: Solar hydrogen; photocatalyst; photoelectrode; water splitting.

\section{Introduction}

In the view of the unlimited resource of solar energy and the abundance of water on earth, producing hydrogen through photocatalytic and photoelectrochemical water splitting under solar irradiation has the great potential to offer a low cost, environmentally friendly, green fuel that does not contribute to greenhouse gas emissions. Since the pioneering work of Fujishima and Honda in 1972 [1], tremendous research on semiconductor-based photocatalysis and photoelectrolysis has yielded a better understanding of the processes involved in photocatalytic and photoelectrochemical water splitting, as well as notable enhancement of energy conversion efficiency for solar hydrogen generation.

Figure 1A presents the basic principles of the photoelectrochemical process for water splitting initially introduced by Fujishima and Honda, who employed a semiconductor (e.g., $\mathrm{TiO}_{2}$ ) working electrode and a Pt counter electrode to compose the photoelectrochemical cell. Once the working electrode is irradiated by light or photons, electrons $\left(\mathrm{e}^{-}\right)$will be excited to the conduction band $(\mathrm{CB})$ with holes $\left(\mathrm{h}^{+}\right)$left in the valence band (VB). Then, the CB electrons transfer to the counter electrode and participate in the hydrogen-evolution half-reaction $\left(2 \mathrm{H}^{+}+2 \mathrm{e}^{-} \rightarrow \mathrm{H}_{2}\right)$, meanwhile the VB holes transfer to the surface of working electrode and participate in the oxygen-evolution half-reaction $\left(\mathrm{H}_{2} \mathrm{O}+2 \mathrm{~h}^{+} \rightarrow 2 \mathrm{H}^{+}+1 / 2 \mathrm{O}_{2}\right)$. Here, the working electrode, $\mathrm{TiO}_{2}$ of n-type semiconductor, acts as an anode. When a p-type semiconductor is used as the working electrode (i.e., cathode), instead, photoexcited CB electrons and VB holes will transfer to the surface of the working and the counter electrode, respectively, participating in the hydrogenevolution and oxygen-evolution half-reactions. Several years later, this concept of photoelectrochemical water splitting was applied by Bard to design a photocatalytic water splitting system using semiconductor particles or powders as photocatalysts $[2,3]$. In such photocatalytic systems as depicted in Figure 1B, photoexcited CB electrons and VB holes transfer to the surface of particulate photocatalysts where they will drive the hydrogen-evolution and oxygen-evolution half-reactions at the specifically designed surface reactive sites, usually created by loading $\mathrm{H}_{2}$ - and $\mathrm{O}_{2}$-evolution co-catalysts.

By investigating the photoelectrochemical and photocatalytic water splitting systems as discussed above, "solaractive nanostructures" (i.e., nanostructured semiconductor photoelectrodes and photocatalysts), which absorb solar light and where solar-driven catalytic reactions take place, play a critical role in the process of solar water splitting. Thus, the design of efficient solar-active nanostructures has undergone considerable research [4-7]. Although a large number of semiconductor materials have been developed as good candidates of photoelectrodes and photocatalysts in past decades, the solar-hydrogen conversion efficiencies of these recognized materials are still not high enough, and as such are far from commercial application. If we look into the basic mechanisms and processes of photoelectrochemical and photocatalytic water splitting, efficient photoelectrodes and photocatalysts should have (1) suitable band gaps and band structures to absorb abundant solar light with wide UV-visible 

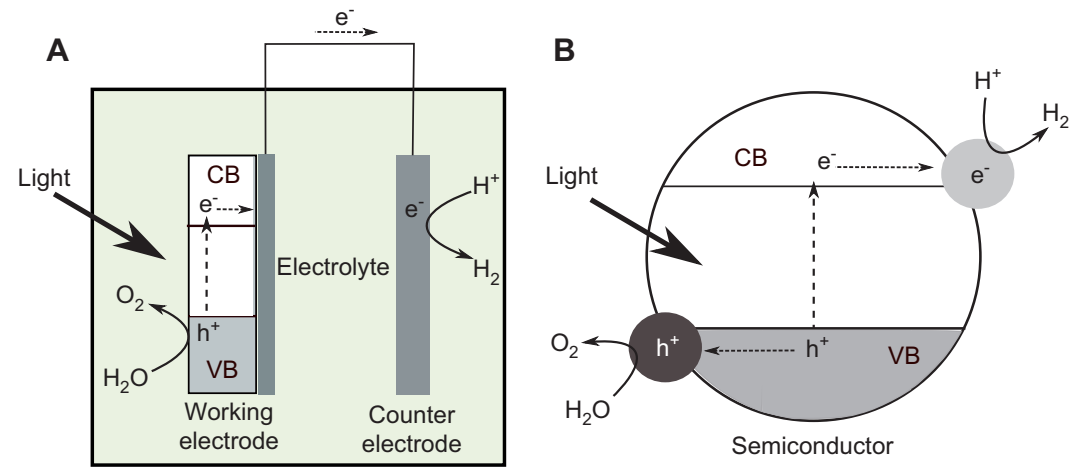

Figure 1 Basic principles of (A) photoelectrochemical and (B) photocatalytic water splitting systems.

wavelength range to drive hydrogen- and oxygen-evolution half-reactions; (2) good charge transfer ability for electrons and holes moving to the semiconductor/electrolyte interface with retarded charge recombination; and (3) high surface catalytic reactivity for half-reactions. Previous research has mainly focused on the above considerations with as much attention given to the issues concerning (1) band gaps and band structures adjustment via ions doping and solid solution; (2) charge transfer enhancement via nanostructure design and semiconductor combination; and (3) surface catalytic reaction promotion via co-catalyst loading. Thorough discussions on various approaches to configurations of efficient solar watersplitting are available in a number of comprehensive recent reviews [7-12]. However, as of yet, semiconductor materials satisfying all these criteria simultaneously have not been identified for high-efficiency, long-term stable and low-cost solar hydrogen conversion.

Recently, some novel concepts of solar-active nanostructures design have been put forward aimed at the breakthrough of solar hydrogen conversion. Among them, the concepts concerning surface engineering, and design of novel nanostructured heterojuctions, and semiconducting photonic crystals appear to be effective to improve photoelectrochemical and photocatalytic performances, which should be helpful to guide further investigations and development of efficient solar-active nanostructures for solar-to-hydrogen conversion. Unlike most previous review articles focusing on traditional modification approaches to improving the efficiencies of photoelectrodes and photocatalysts, this overview will emphasize these newly developed concepts and strategies of solar-active nanostructures design, in which brief discussions on surface engineering, novel nanostructured heterojuctions, and semiconducting photonic crystals will be presented, as the timely and instructive update and supplement to the previous reviews on photoelectrochemical and photocatalytic water splitting.

\section{Surface engineering}

In general, the surface of catalytic materials, where solar light is absorbed and catalytic reaction takes place, determines the activities of solar water splitting reaction to a great extent.
Surface properties such as surface structure and active reaction sites, which are mainly related to the optical property, surface charge transfer ability and catalytic reactivity of the semiconductor materials, are very important. Thus, respectable research efforts have been dedicated to the surface engineering of the photoelectrodes and photocatalysts with the view to enhance solar absorption, improve charge separation as well as promote catalytic half-reaction. In this section, a brief introduction to some representative and innovative studies on surface engineering will be presented.

\subsection{Disorder-engineered surfaces}

$\mathrm{TiO}_{2}$, as the most investigated photoelectrode and photocatalytic material, has a large band gap of about $3.2 \mathrm{eV}$, which limits its visible and infrared light absorption for solar water splitting. Doping of either metal or non-metal ions has proved effective to narrow the band gap of $\mathrm{TiO}_{2}$ by introducing acceptor or donor levels in the forbidden band, which makes $\mathrm{TiO}_{2}$ responsive to visible light [13]. However, because the dopingcreated energy levels could also act as charge recombination centers, the solar water splitting activities of doped $\mathrm{TiO}_{2}$ are limited and still at a low level.

Recently, Mao and his team [14] demonstrated a conceptually different approach to enhancing solar absorption of $\mathrm{TiO}_{2}$ nanocrystals by introducing disorder in the surface layers. The disorder-engineered $\mathrm{TiO}_{2}$ was typically synthesized by the hydrogenation of nanophase $\mathrm{TiO}_{2}$ of approximately $8 \mathrm{~nm}$ in diameter in a 20.0-bar $\mathrm{H}_{2}$ atmosphere at approximately $200^{\circ} \mathrm{C}$ for 5 days, accompanied by a dramatic color change from white to black. After hydrogenation, the black $\mathrm{TiO}_{2}$ nanocrystals maintained the anatase structure; however, the surfaces of $\mathrm{TiO}_{2}$ nanocrystals became disordered where the disordered outer layer surrounding a crystalline core was approximately $1 \mathrm{~nm}$ in thickness (Figure 2A). As revealed in Figure $2 \mathrm{~B}$, the band gap of the unmodified white $\mathrm{TiO}_{2}$ nanocrystals was approximately $3.30 \mathrm{eV}$, while the onset of optical absorption of the black disorder-engineered $\mathrm{TiO}_{2}$ nanocrystals was lowered to approximately $1.0 \mathrm{eV}(\sim 1200 \mathrm{~nm})$, which suggests that the optical gap of the black $\mathrm{TiO}_{2}$ nanocrystals was substantially narrowed by intraband transitions. The first-principles density functional theory (DFT) 
A

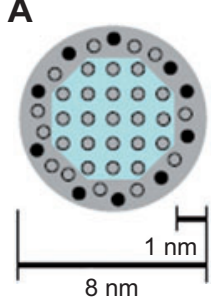

B

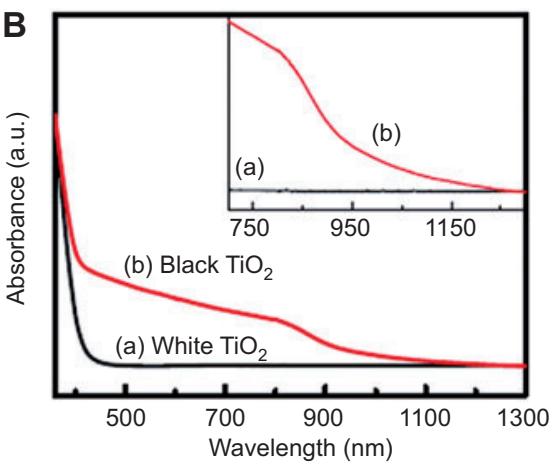

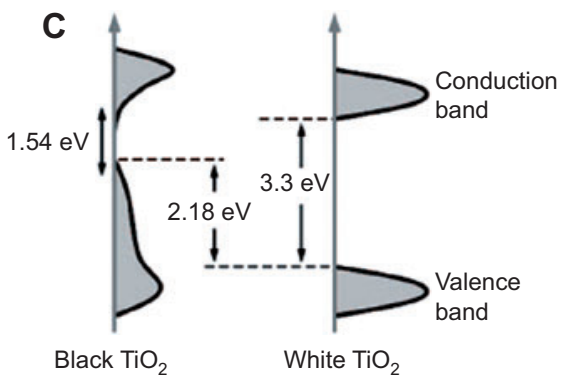

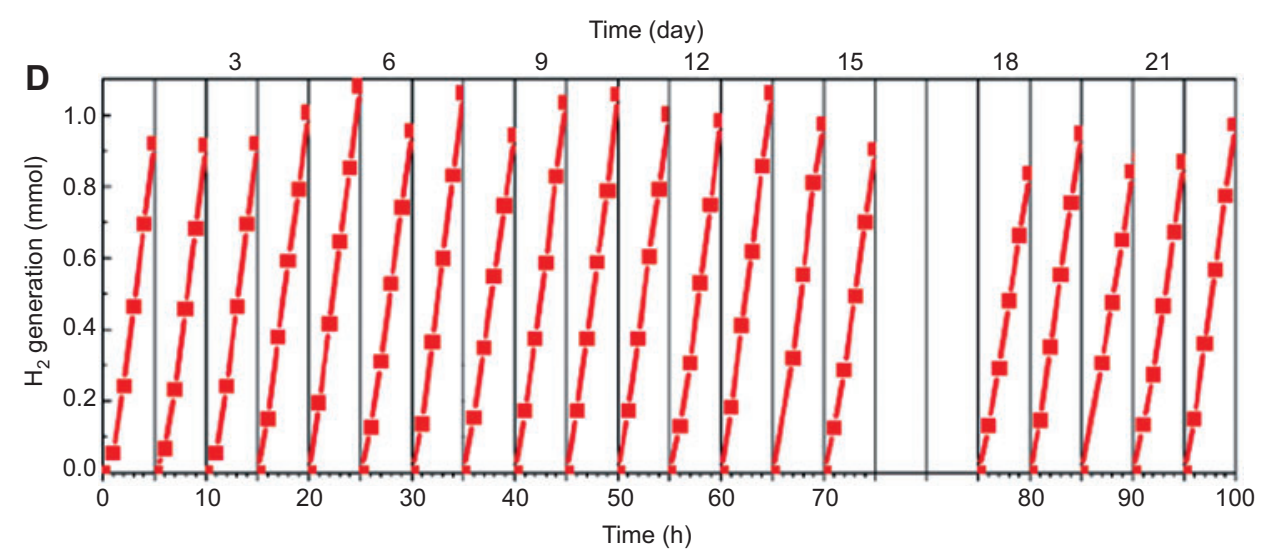

Figure 2 (A) Schematic illustration of the structure of disorder-engineered black $\mathrm{TiO}_{2}$. (B) Spectral absorbance of the white and black $\mathrm{TiO}_{2}$ nanocrystals. The inset enlarges the absorption spectrum in the range from approximately 750 to $1200 \mathrm{~nm}$. (C) Schematic illustration of the DOS of disorder-engineered black $\mathrm{TiO}_{2}$ nanocrystals, as compared to that of unmodified $\mathrm{TiO}_{2}$ nanocrystals. (D) Cycling measurements of hydrogen gas generation through direct photocatalytic water splitting with disorder-engineered black $\mathrm{TiO}_{2}$ nanocrystals under simulated solar light. Experiments were conducted over a 22-day period, with $100 \mathrm{~h}$ of overall solar irradiation time. Reprinted with permission from ref. [14]. Copyright 2011 American Association for the Advancement of Science.

suggested that lattice disorder accounted for the mid-gap states; hydrogen stabilized the lattice disorders by passivating their dangling bonds. The lower-energy mid-gap states lying below the Fermi level contributed to a large blue shift of the valence band edge. As illustrated in Figure 2C, optical transitions from the blue-shifted valence band edge to these conduction band tail states arising from disorder are presumably responsible for optical absorption onset around $1.0 \mathrm{eV}$ in black $\mathrm{TiO}_{2}$. The disorder-engineered $\mathrm{TiO}_{2}$ nanocrystals exhibited substantial activity and stability in the solardriven production of hydrogen from water with the use of a sacrificial reagent. As shown in Figure 2D, during a 22-day testing period, black $\mathrm{TiO}_{2}$ nanocrystals produced hydrogen continuously at a steady rate, without an obvious decrease in hydrogen evolution rate. This hydrogen production rate (10 $\mathrm{mmol} \cdot \mathrm{h}^{-1} \cdot \mathrm{g}^{-1}$ of photocatalysts), with solar energy conversion efficiency as high as $24 \%$, is about two orders of magnitude greater than the yields of most semiconductor photocatalysts $[4,7]$. This is because the disorder-engineered black $\mathrm{TiO}_{2}$ can efficiently harvest photons from UV to near-infrared for photocatalysis, while the localization of both photoexcited electrons and holes prevents fast recombination.

Further investigation on the role of hydrogenation as well as the mechanism of high photoactivity of surface disordered
$\mathrm{TiO}_{2}$ was conducted by $\mathrm{Lu}$ et al. [15] based on first-principles calculations. By taking into account the synergic effect of $\mathrm{Ti}-\mathrm{H}$ and $\mathrm{O}-\mathrm{H}$ bonds, they found that hydrogen atoms can be chemically absorbed both on $\mathrm{Ti}_{5 \mathrm{c}}$ and $\mathrm{O}_{2 \mathrm{c}}$ atoms for (101), (001), and (100) surfaces, which not only induced the lattice disorders but also interacted strongly with the Ti $3 \mathrm{~d}$ and $\mathrm{O} 2 \mathrm{p}$ states, resulting in a considerable contribution to the mid-gap states. Thus, the optical absorption was dramatically increased due to the introduced localized mid-gap states. Moreover, the photogenerated electrons and holes could be separated efficiently by the electron-hole flow between different facets, which led to the high solar hydrogen conversion efficiency of the disorder-engineered black $\mathrm{TiO}_{2}$.

Following on the concept of surface disordering of $\mathrm{TiO}_{2}$ nanocrystals by hydrogenation, $\mathrm{TiO}_{2}$ nanowires were treated in hydrogen atmosphere at various temperatures in a range of $200-550^{\circ} \mathrm{C}[16]$ to understand the interplay between the light absorption and photoelectrochemical performance for water splitting. As shown in Figure 3, the color of the hydrogentreated rutile $\mathrm{TiO}_{2}$ nanowire $\left(\mathrm{H}: \mathrm{TiO}_{2}\right)$ films changed from white to yellowish green and finally to black depending on the hydrogen annealing temperature. The visible and near-infrared light absorption can be attributed to the oxygen vacancies created in the band gap of $\mathrm{TiO}_{2}$ nanowires. In comparison 

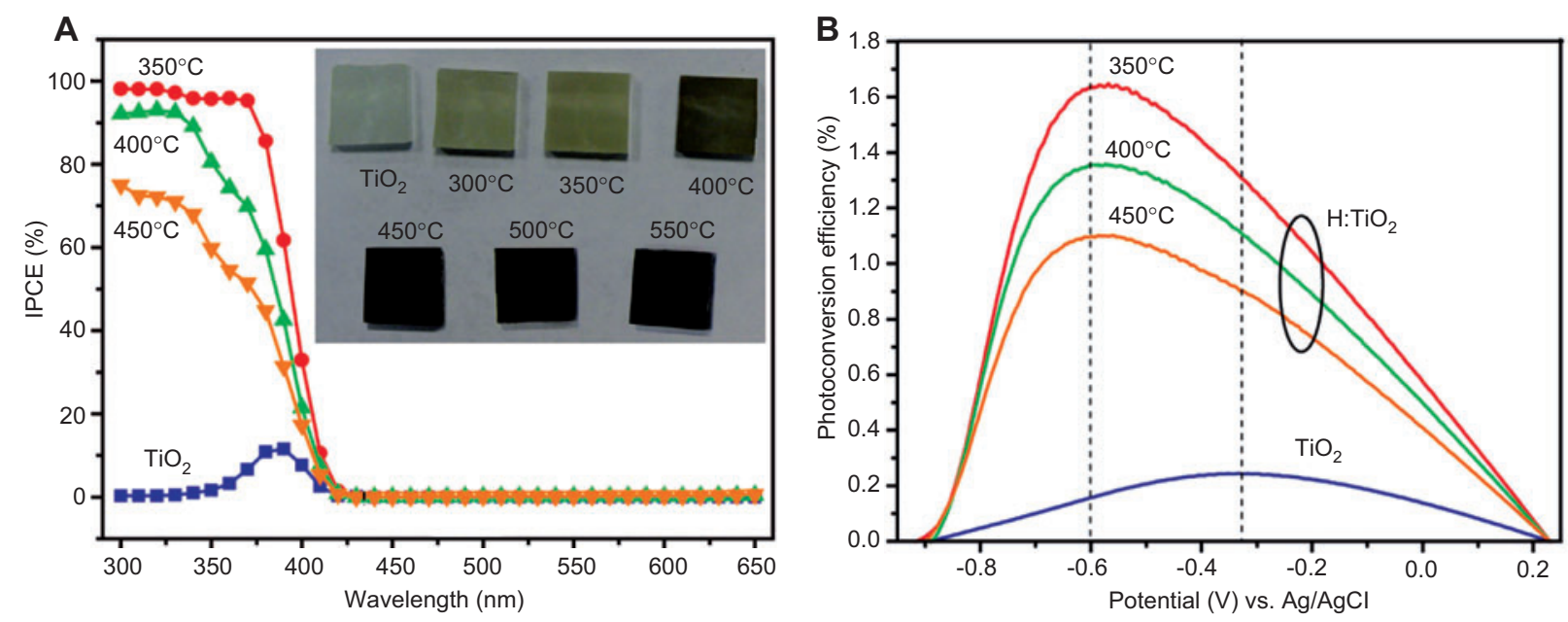

Figure 3 (A) IPCE spectra of pristine $\mathrm{TiO}_{2}$ and $\mathrm{H}: \mathrm{TiO}_{2}$ nanowires prepared at 350,400 , and $450^{\circ} \mathrm{C}$, collected at the incident wavelength range from 300 to $650 \mathrm{~nm}$ at a potential of $-0.6 \mathrm{~V}$ vs. $\mathrm{Ag} / \mathrm{AgCl}$. Inset: Digital pictures of pristine $\mathrm{TiO}_{2}$ and $\mathrm{H}_{\mathrm{TiO}}$ nanowires annealed in hydrogen at various temperatures $\left(300,350,400,450,500\right.$, and $\left.550^{\circ} \mathrm{C}\right)$. (B) Calculated photoconversion efficiencies for the pristine $\mathrm{TiO}_{2}$ and $\mathrm{H}_{2} \mathrm{TiO}_{2}$ nanowire samples, as a function of applied potential vs. $\mathrm{Ag} / \mathrm{AgCl}$. The dashed lines highlight the optimal potentials for each sample. Reprinted with permission from ref. [16]. Copyright 2011 American Chemical Society.

to pristine $\mathrm{TiO}_{2}$ rutile nanowires, the $\mathrm{H}: \mathrm{TiO}_{2}$ samples yielded substantially enhanced photocurrent densities, which was mainly due to the greatly improved photoactivity in the UV region. This is because hydrogen treatment increases the donor density of $\mathrm{TiO}_{2}$ nanowires by three orders of magnitudes, via creating a high-density of oxygen vacancies that serve as electron donors. The highest photocurrent density of $\sim 1.97$ $\mathrm{mA} / \mathrm{cm}^{2}$ at $-0.6 \mathrm{~V}$ vs. $\mathrm{Ag} / \mathrm{AgCl}$, in $1 \mathrm{~m} \mathrm{NaOH}$ solution under the illumination of simulated solar light corresponded to a solar-to-hydrogen (STH) efficiency of $\sim 1.63 \%$, which is the best value reported for a $\mathrm{TiO}_{2}$ photoanode. Similar enhancements in photocurrent were also observed in anatase $\mathrm{H}: \mathrm{TiO}_{2}$ nanotubes.

The feasible fabrication of highly photoactive $\mathrm{TiO}_{2}$ nanomaterials with disordered surface layers by hydrogenation opens up new opportunities for breakthrough innovation in the field of solar energy conversion, including photocatalysis, photoelectrochemical water splitting, and dye-sensitized solar cells. Surface disorder engineering of nanocrystals via high-pressure hydrogenation can be expected to be an effective way to facilitate solar energy conversion efficiency.

\subsection{Oxygen evolution catalyst (OEC) loading}

Another strategy of surface engineering that can be used to enhance the photocatalytic and photoelectrochemical activity of semiconductor materials is to create surface reactive sites for water reduction and oxidation reactions. It is well known that some noble metals, such as $\mathrm{Pt}, \mathrm{Ru}, \mathrm{Au}$, etc., and metal oxides, such as $\mathrm{NiO}_{x}, \mathrm{Rh} / \mathrm{Cr}_{2} \mathrm{O}_{3}$, etc., perform as good water reduction co-catalysts by entrapping electrons from semiconductors [7, 17]. While considering water oxidation as the rate-determined step of the four-electron/hole water splitting process, the slow kinetics for water oxidation [18], giving rise to the large overpotentials for oxygen evolution over photoanodes, results in hole accumulation at the surface and then subsequent surface recombination before the positive potentials are sufficient for considerable charge transfer across the photoanode/eletrolyte interface. Thus, the overpotentials for water oxidation should be lowered to have a less kinetic barrier of interfacial charge-transfer for the high photoactivity for water splitting. To this end, water oxidation cocatalysts (i.e., oxygen evolution catalysts, OEC) are used to modify the surface of water splitting electrodes by creating surface reactive sites to reduce the activation energy for water oxidation. In this section, we will focus on some newly developed OECs integrated with photoassisted electrodes for efficient water splitting.

$\mathrm{IrO}_{2}$, in terms of overpotential, is an efficient OEC [1922], and has been reported to modify the surface of different kinds of photoanodes for enhanced solar water splitting [2326]. Domen and co-workers demonstrated the possible application of (oxy)nitride semiconductors, such as $\mathrm{Ta}_{3} \mathrm{~N}_{5}$ [24], $\mathrm{SrNbO}_{2} \mathrm{~N}$ [25], $\mathrm{LaTiO}_{\mathrm{x}} \mathrm{N}_{\mathrm{y}}$ [26], and $\mathrm{TaON}$ [27], as photoanodes for water splitting by loading $\mathrm{IrO}_{2}$ nanoparticles on their surfaces to suppress the self-oxidation of the photoanode and promote the oxidation of water. As shown in Figure 4, the $\mathrm{IrO}_{2}$ loading was found to greatly improve the activity and stability of these (oxy)nitride photoelectrodes during photoirradiation. For example, in Figure 4D, the photocurrent of a bare $\mathrm{TaON}$ electrode decreased sharply to a negligible level within $10 \mathrm{~min}$, due to the self-oxidative decomposition of TaON. After loading $\mathrm{IrO}_{2}$ nanoparticles, which most likely acted as oxidation reactive sites to scavenge holes for water oxidation instead of $\mathrm{TaON}$ self-oxidation, the decreases in both photocurrent and $\mathrm{N}$ content (inset) were noticeably suppressed. A high incident photon-to-current conversion efficiency (IPCE, ca. $76 \%$ at $400 \mathrm{~nm}$ at $0.6 \mathrm{~V}$ vs. $\mathrm{Ag} / \mathrm{AgCl}$ ) was 

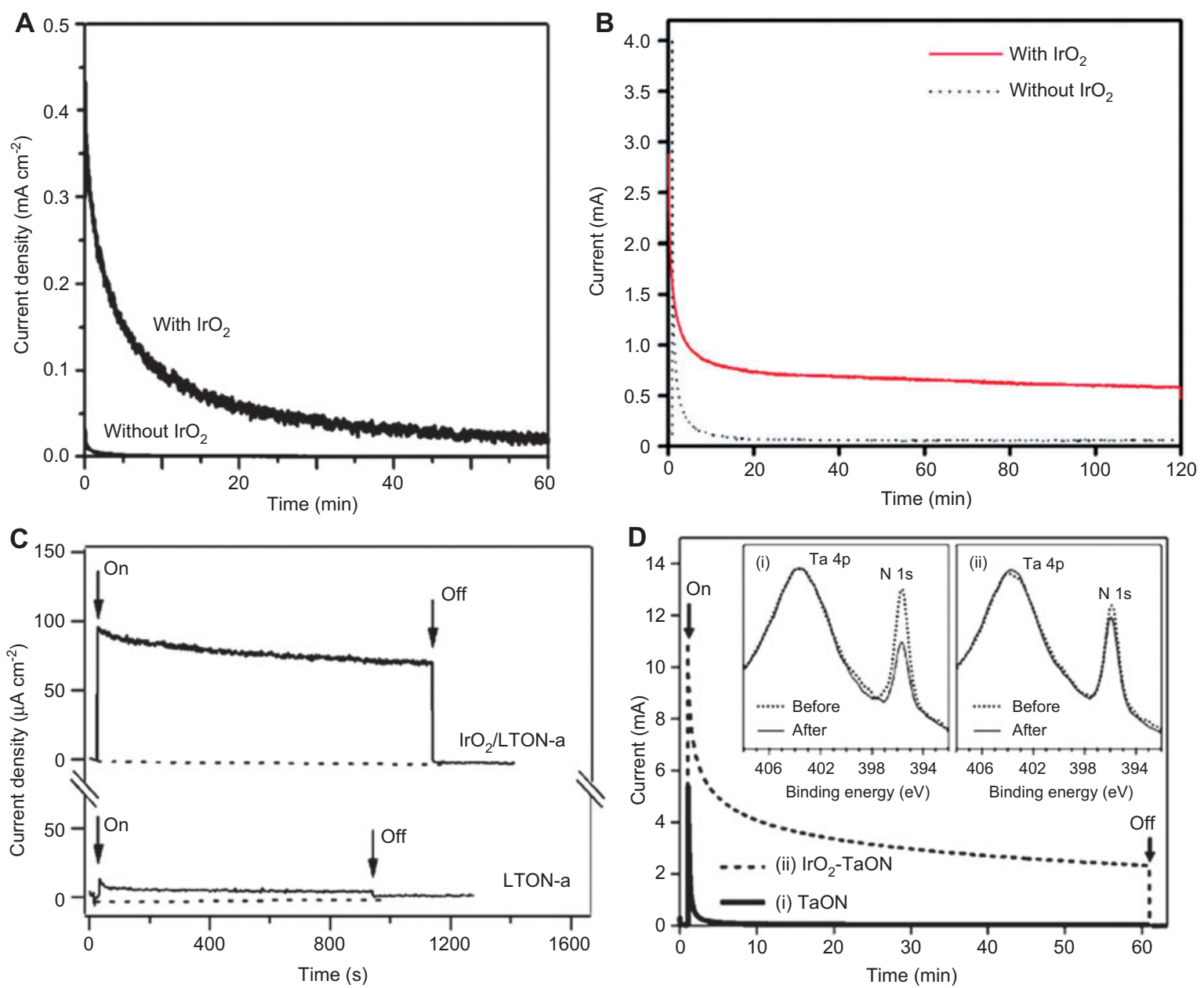

Figure 4 (A) Current-time curves of $\mathrm{Ta}_{3} \mathrm{~N}_{5}$ and $\mathrm{IrO}_{2} / \mathrm{Ta}_{3} \mathrm{~N}_{5}$ in $0.1 \mathrm{M} \mathrm{Na}_{2} \mathrm{SO}_{4}$ aqueous solution ( $\mathrm{pH}=8.5$ ) under irradiation by a $300 \mathrm{~W}$ Xe lamp equipped with a short-cut-off filter. The potential was kept at $0.5 \mathrm{~V}$ vs. $\mathrm{Ag} / \mathrm{AgCl}$. Reprinted with permission from ref. [24]. Copyright 2011 Elsevier. (B) Current-time curves in aqueous $0.5 \mathrm{M} \mathrm{Na}_{2} \mathrm{SO}_{4}$ solution $(\mathrm{pH} \approx 6)$ for postnecked $\mathrm{SrNbO}_{2} \mathrm{~N}$ electrodes $\left(6 \mathrm{~cm}^{2}\right)$ with and without modification by colloidal $\mathrm{IrO}_{2}$ at $+1.55 \mathrm{~V}$ vs. RHE under visible-light irradiation $(\lambda>420 \mathrm{~nm})$. Reprinted with permission from ref. [25]. Copyright 2011 American Chemical Society. (C) Current-time evolution for $\mathrm{LaTiO}_{\mathrm{x}} \mathrm{N}_{\mathrm{y}}$ and $\mathrm{IrO}_{2} / \mathrm{LaTiO}_{\mathrm{x}} \mathrm{N}_{\mathrm{y}}$ films in aqueous $0.5 \mathrm{M} \mathrm{Na}_{2} \mathrm{SO}_{4}$ solution at +1.0 $\mathrm{V}$ vs. $\mathrm{Ag} / \mathrm{AgCl}$ under visible irradiation. Reprinted with permission from ref. [26]. Copyright 2009 American Chemical Society. (D) Currenttime evolution for $\mathrm{TaON}$ and $\mathrm{IrO}_{2}-\mathrm{TaON}$ electrodes $\left(6 \mathrm{~cm}^{2}\right)$ at $+0.6 \mathrm{~V}$ (vs. $\mathrm{Ag} / \mathrm{AgCl}$ ) and XPS spectra of electrodes before and after $1 \mathrm{~h}$ of irradiation (inset). Reprinted with permission from ref. [27]. Copyright 2010 American Chemical Society.

obtained over the $\mathrm{IrO}_{2}$-loaded TaON electrode, which is the highest IPCE value ever reported for (oxy)nitride photoelectrode. However, self-oxidation was not entirely suppressed by the loading of the $\mathrm{IrO}_{2}$ cocatalyst, because the loading method of soaking led to the aggregation of most $\mathrm{IrO}_{2}$ nanoparticles on a relatively small fraction of the TaON surface with large portions of the TaON surface uncovered. Recently, $\mathrm{IrO}_{2}$ nanoparticles were loaded onto the hematite photoanode by Tilley et al. using the electrophoretic deposition method, which was found to be superior to methods such as soaking [23]. A dramatic cathodic shift in the possible photocurrent onset potential and an increase in the plateau photocurrent were observed after $\mathrm{IrO}_{2}$ loading, indicating that $\mathrm{IrO}_{2}$ nanoparticles acting as $\mathrm{OEC}$ lowered the overpotentials and hence improved the photoactivity for water oxidation over hematite photoanodes.
Many other metal oxides, such as $\mathrm{RuO}_{2}, \mathrm{Rh}_{2} \mathrm{O}_{3}, \mathrm{Co}_{3} \mathrm{O}_{4}$, and $\mathrm{Mn}_{3} \mathrm{O}_{4}$, have been investigated as OECs for photochemical water oxidation as deposited on powdered photocatalysts in solution [28-31]. In Bard's study on the screening of OECs for $\mathrm{W}$-doped $\mathrm{BiVO}_{4}$ photoelectrodes by scanning electrochemical microscopy, $\mathrm{Co}_{3} \mathrm{O}_{4}$ electrocatalysts showed an enhanced photocurrent for photoelectrochemical water oxidation, while the other metal oxide catalysts including $\mathrm{IrO}_{\mathrm{x}}$ were not effective [32]. Some metal oxide mixtures, like $\mathrm{NiFe}$ mixed oxides, have been observed to significantly lower the overpotential for the oxygen evolution (water oxidation) reaction and exhibit high stability in electrochemical systems [33-36]. NiFe binary oxide electrocatalysts were evaluated by McFarland et al. to facilitate the oxygen evolution reaction on semiconducting metal-oxide photoelectrodes [37]. They found that $\mathrm{NiFe}$ oxide electrocatalysts electrodeposited from 
different precursors on Ti doped hematite created electrocatalysts with significantly different properties and increasing $\mathrm{Ni}$ content. In the case of the NiFe oxide electrocatalysts deposited from the $\mathrm{Ni}^{2+} / \mathrm{Fe}^{3+}$ precursors, significant increases of the photocurrent by as much as five times from the IPCE at zero bias were observed as compared to the control sample. Hong et al. [38] reported that photodeposition of a Ni-Bi OEC on hematite nanorods showed $>200 \mathrm{mV}$ cathodic shift of the onset potential for water oxidation and a 9.5 -fold enhancement in the photocurrent density at $0.86 \mathrm{~V}$ vs. RHE compared to that of the parent hematite photoanode. However, the photocurrent improvement in a high bias region was reduced, due to a kinetic limitation of oxygen evolution at the $\mathrm{Ni}-\mathrm{Bi} /$ electrolyte interface which introduced a higher possibility of surface charge recombination.

By mimicking the oxygen evolving complex of photosystem II, which contains an oxygen bridged manganese (Mn) cluster with two redox active Mn ions [39, 40], efficient water oxidation catalysis was achieved in a photoelectrochemical device made by impregnating a synthetic tetranuclear-manganese cluster into a Nafion matrix [41]. The cycling between the $\mathrm{Mn}$ (II) photoreduced product and an oxidized, disordered $\mathrm{Mn}$ (III/IV) oxide phase was demonstrated to form the basis of the water oxidation catalysis. Similar to this Mn catalyst that spontaneously reassembles once dissociated in catalytic terms, a cobalt (Co) catalyst, forming upon the oxidative polarization of an inert indium tin oxide electrode in phosphate-buffered water containing cobalt (II) ions, could catalyze oxygen evolution via a catalytic reaction cycle among $\mathrm{Co}^{2+}-\mathrm{Co}^{3+}$, and $\mathrm{Co}^{4+}$-oxo oxidation states [42]. Co-based OECs were further used to modify the surface of hematite photoelectrodes for improved photoelectrochemical water splitting [43, 44]. Especially, an IPCE of $42 \%$ at $370 \mathrm{~nm}$ and $1.23 \mathrm{~V}$ vs. RHE was achieved on the Si-doped $\mathrm{Fe}_{2} \mathrm{O}_{3}$ photoelectrodes by a cobalt treatment in a $\mathrm{Co}\left(\mathrm{NO}_{3}\right)_{2}$ aqueous solution [44]. The proposed water oxidation cycle comprising states $\mathrm{S}_{0}$ to $\mathrm{S}_{4}$, as shown in Figure 5, claimed that the electrocatalytic activity of cobalt may be responsible for an enhancement of the IPCE.

Recently, cobalt(II)-phosphate complexes (Co-Pi) have been demonstrated to work effectively as OEC in photoelectrolysis when coupled to $\mathrm{ZnO}$ [45], hematite [46-48], $\mathrm{WO}_{3}$ [49], $\mathrm{BiVO}_{4}[50-52]$, and Si electrodes [53, 54]. In all cases, Co-Pi deposition onto the photoanode surface yielded large cathodic shifts of the onset potentials or enhanced performances for water oxidation. This is because Co-Pi deposition facilitated interfacial hole transfer from photoanode to Co-Pi, resulting in retardation of electron-hole recombination and enhanced charge separation in such composites. For example, as shown in Figure 6, modification of $\mathrm{W}: \mathrm{BiVO}_{4}$ photoanode surfaces with Co-Pi yielded a very large $(\sim 440 \mathrm{mV})$ cathodic shift in onset potential for sustained photoelectrochemical water oxidation and substantial improvements of photocurrents especially at low applied potentials [50]. Photoelectrochemical experiments with $\mathrm{H}_{2} \mathrm{O}_{2}$ as a surrogate substrate revealed that interfacing Co-Pi with these $\mathrm{W}: \mathrm{BiVO}_{4}$ photoanodes almost completely eliminated losses due to surface electron-hole recombination. The thickness of the Co-Pi layer was shown to play an important role in photoanode performance, with

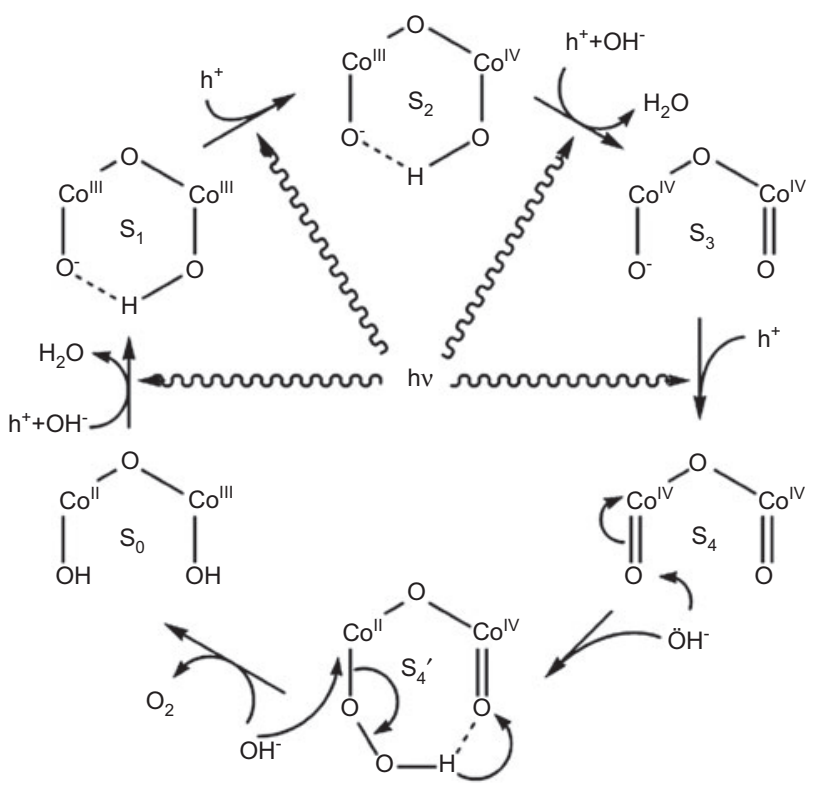

Figure 5 Mechanistic proposal for water photooxidation at the cobalt-modified hematite surface. $\left(\mathrm{S}_{0}\right.$ to $\left.\mathrm{S}_{4}\right)$ : capture of four photogenerated holes by vicinal Co centers accompanied by deprotonation of surface hydroxyl groups creates highly electrophilic oxo groups on $\mathrm{Co}^{\mathrm{IV}}$. Nucleophilic attack from hydroxide on one $\mathrm{Co}^{\mathrm{IV}}=\mathrm{O}$ results in O-O bond formation and a peroxo intermediate $\left(\mathrm{S}_{4}{ }^{\prime}\right)$. This decomposes to dioxygen under hydrogen transfer to the second $\mathrm{Co}^{\mathrm{IV}}=\mathrm{O}$. Rehydroxylation of the dangling $\mathrm{Co}^{\mathrm{II}}$ coordination site by the electrolyte closes the cycle. Reprinted with permission from ref. [44]. Copyright 2006 American Chemical Society.

increased Co-Pi thicknesses reducing overpotentials but also impairing the ability to sustain high current densities [55]. Thick catalyst layers reduced the ability of productive water oxidation to compete with non-productive surface electronhole recombination. This kinetic bottleneck could be largely overcome by more sparse deposition of Co-Pi onto the surface of photoanodes. Zhong et al. [48] showed that photo-assisted electrodeposition of Co-Pi yielded superior $\alpha-\mathrm{Fe}_{2} \mathrm{O}_{3}$ photoanodes for photoelectrochemical water oxidation than other approaches such as electrodeposition of $\mathrm{Co}-\mathrm{Pi}$ and $\mathrm{Co}^{2+}$ wet impregnation, by providing a more uniform distribution of Co-Pi onto $\alpha-\mathrm{Fe}_{2} \mathrm{O}_{3}$. Steinmiller and Choi [45] demonstrated the photochemical deposition of Co-based catalysts based on $\mathrm{Co}^{2+} / \mathrm{Co}^{3+}$ oxidation in an aqueous neutral phosphate medium as an efficient route to couple an OEC and a photoanode. As shown in Figure 7, photodeposition provided an efficient way to couple oxygen evolution catalysts with photoanodes by naturally placing the catalysts where they can best use photogenerated holes for solar $\mathrm{O}_{2}$ production.

To capture the basic functional elements of a leaf, Nocera's team [56] recently developed the solar water-splitting cells operating in near-neutral $\mathrm{pH}$ conditions both with and without connecting wires. As shown in Figure 8, the cells consisted of a triple junction, amorphous silicon photovoltaic interfaced to hydrogen- and oxygen-evolving catalysts (OEC) made from an alloy of earth-abundant metals (NiMoZn) and a cobalt- 

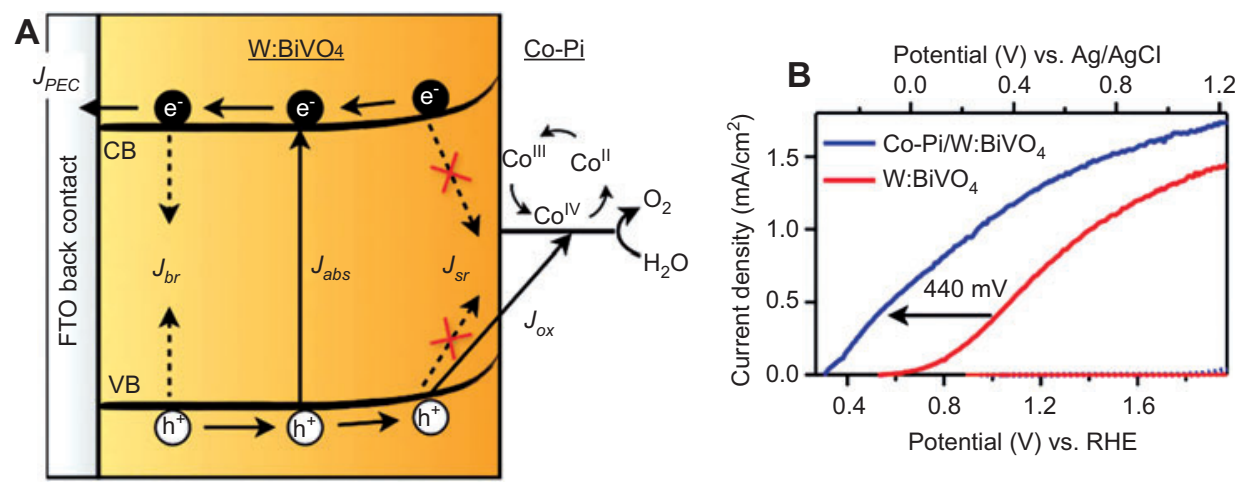

Figure 6 (A) Energy diagram showing the kinetic processes active in the Co-Pi/W:BiVO photoanodes. Electron-hole pairs are generated with a current density associated with photon absorption $\left(\mathrm{J}_{\text {abs }}\right)$ and can recombine non-productively with current densities associated with radiative or non-radiative bulk $\left(\mathrm{J}_{\mathrm{br}}\right)$ and surface $\left(\mathrm{J}_{\mathrm{sr}}\right)$ recombination. Electron collection at the back contact $\left(\mathrm{J}_{\mathrm{PEC}}\right)$ and hole transfer to the oxidizable substrate $\left(\mathrm{J}_{\mathrm{ox}}\right)$ are productive processes contributing to photoelectrochemical device efficiency. (B) Current density-voltage (J-V) curves measured for a $\mathrm{W}: \mathrm{BiVO}_{4}$ photoanode before (red) and after (blue) photoassisted electrodeposition of Co-Pi under front-side illumination (solid line) and in the dark (dotted line). Experiments were performed with 1 sun, AM 1.5 simulated solar irradiation in $0.1 \mathrm{~m} \mathrm{KPi} \mathrm{buffer} \mathrm{at} \mathrm{pH} 8$ at a scan rate of $10 \mathrm{mV} / \mathrm{s}$. Reprinted with permission from ref. [50]. Copyright 2011 American Chemical Society.
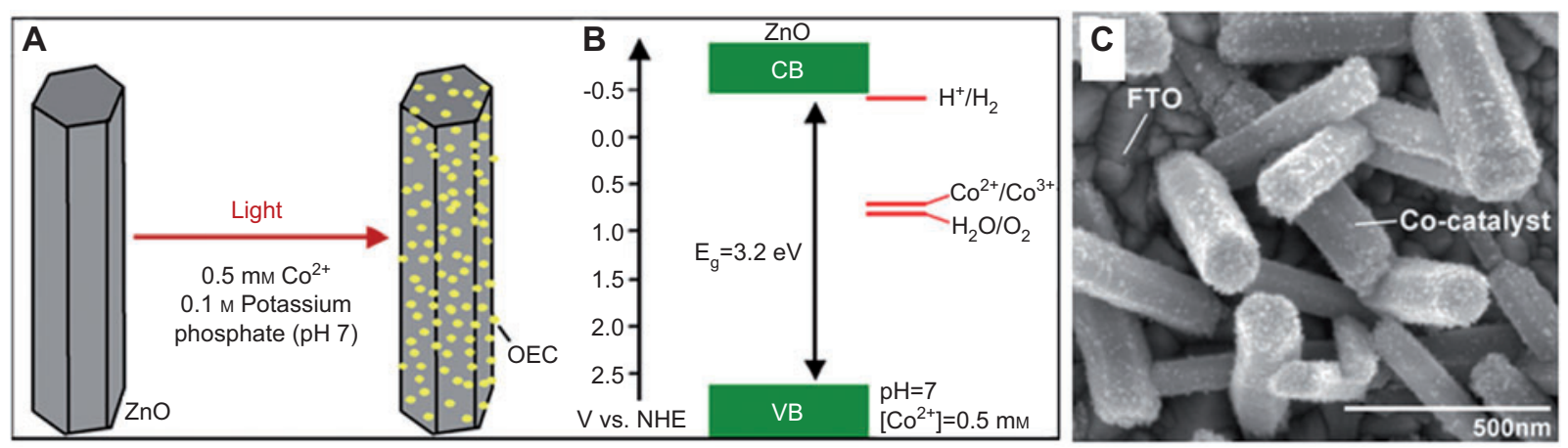

Figure 7 Schematic representation of (A) photochemical deposition of the Co-based catalyst on ZnO and (B) relevant energy levels. (C) SEM images of Co-based catalyst nanoparticles photochemically deposited on $\mathrm{ZnO}$ for $30 \mathrm{~min}$. Reprinted with permission from ref. [45]. Copyright 2009 the National Academy of Sciences.
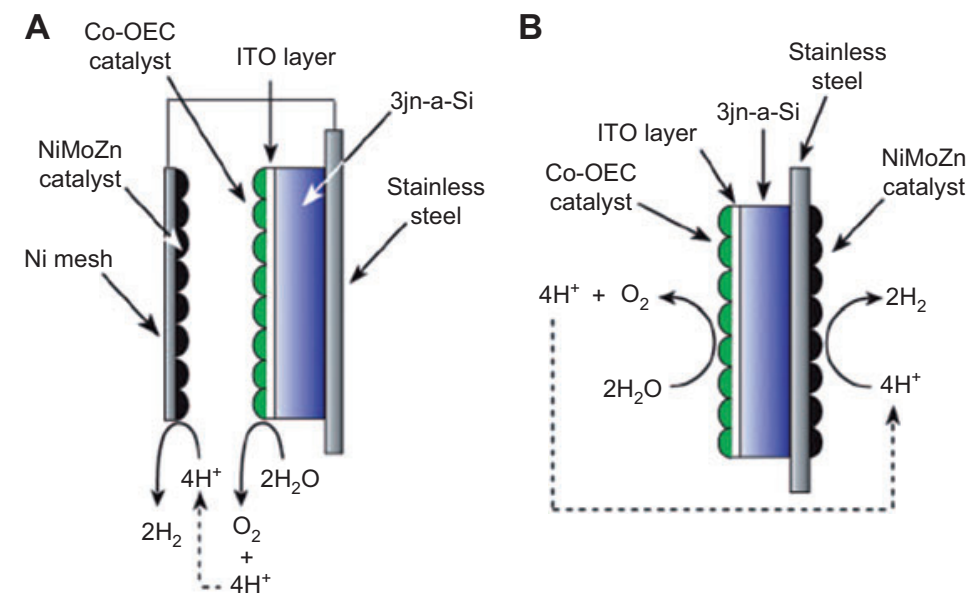

Figure 8 (A) Wired and (B) wireless photoelectrochemical (PEC) cells. Reprinted with permission from ref. [56]. Copyright 2011 American Association for the Advancement of Science. 
borate catalyst (Co-B), respectively. The devices, as the highest performing cells, carried out the solar-driven watersplitting reaction at efficiencies of $4.7 \%$ for a wired configuration and $2.5 \%$ for a wireless configuration when illuminated with 1 sun of AM 1.5 simulated sunlight.

\subsection{Surface overlayer design}

In a discussion on the importance of surface regime for a photoelectrode in the solar water splitting reaction it is worthwhile commenting on the influence of surface outer-layer coatings, and especially on their influence on the optical and electronic properties and surface reactivity, etc. Thus the design of functional surface overlayers that permit electron tunneling, enhance optical absorption and reaction kinetics, passivate dangling bonds, or possess unique electronic structures, comes to benefit solar water splitting, especially the performance-limiting half-reaction of water oxidation.

In the authors' own laboratory, particular attention has been paid to one-dimensional core/shell nanorod structures, as structures of this type are most likely to utilize the benefits afforded by designed surface overlayer coating and likely to show functional behavior relating to the core/shell interfacial region. A novel core/shell nanoarray, based on quantumconfined and visible light-active $\alpha-\mathrm{Fe}_{2} \mathrm{O}_{3}$ nanorods and their surface modified with thin $\mathrm{WO}_{3}$ overlayer, was fabricated by a combination of aqueous chemical synthesis and vapor phase deposition [57]. The observation of the activity in the visible light region (>550 nm), in Figure 9A, suggested that a significant quantity of holes originating from visible-light excitations, which occurred in the $\alpha-\mathrm{Fe}_{2} \mathrm{O}_{3}$ core rather than the $\mathrm{WO}_{3}$ overlayer due to the large band gap of $\mathrm{WO}_{3}$ (ca. 3 $\mathrm{eV}$ ), was extracted before recombining with electrons traveling to the back contact. Moreover, the enhanced photoelectrochemical activity as shown Figure 9B indicated that the modification of $\alpha-\mathrm{Fe}_{2} \mathrm{O}_{3}$ nanorods with $\mathrm{WO}_{3}$ overlayer promoted the extraction of surface-trapped holes from the $\alpha-\mathrm{Fe}_{2} \mathrm{O}_{3}$ core. However, from the viewpoint of bulk semiconductor physics, there should be an energy barrier of ca. $0.5 \mathrm{eV}$ for hole injection from $\alpha-\mathrm{Fe}_{2} \mathrm{O}_{3}$ into $\mathrm{WO}_{3}$ [58]. Thus, the visible light photoactivity performed by hole extraction from the core should be directly related to the unique futures of the core/shell nanoscale architecture, such as interface electronic orbital reconstruction via $p-d$ orbital hybridization as well as quantum-mechanical tunneling. Further research conducted by Mao, Vayssieres, and their colleagues indicated that the formation of core/shell heterostructures comprised of an $\alpha-\mathrm{Fe}_{2} \mathrm{O}_{3}$ core coated with a $\mathrm{TiO}_{2}$ overlayer resulted in an emergent degree of $p-d$ orbital hybridization and spontaneous electron enrichment in the interfacial region and thus possessed a unique electronic structure [59]. These results opened new avenues to engineer the electrical and optical properties of transition metal oxide hetero-nanostructures, for devices utilizing transitions to and from their associated electronic states, most notably those for solar fuel generation and photovoltaics.

Smith et al. successfully fabricated unique quasi-coreshell nanorod arrays of $\mathrm{TiO}_{2} / \mathrm{WO}_{3}$ and $\mathrm{WO}_{3} / \mathrm{TiO}_{2}$ by dynamic shadowing growth using glancing angle deposition [60]. The
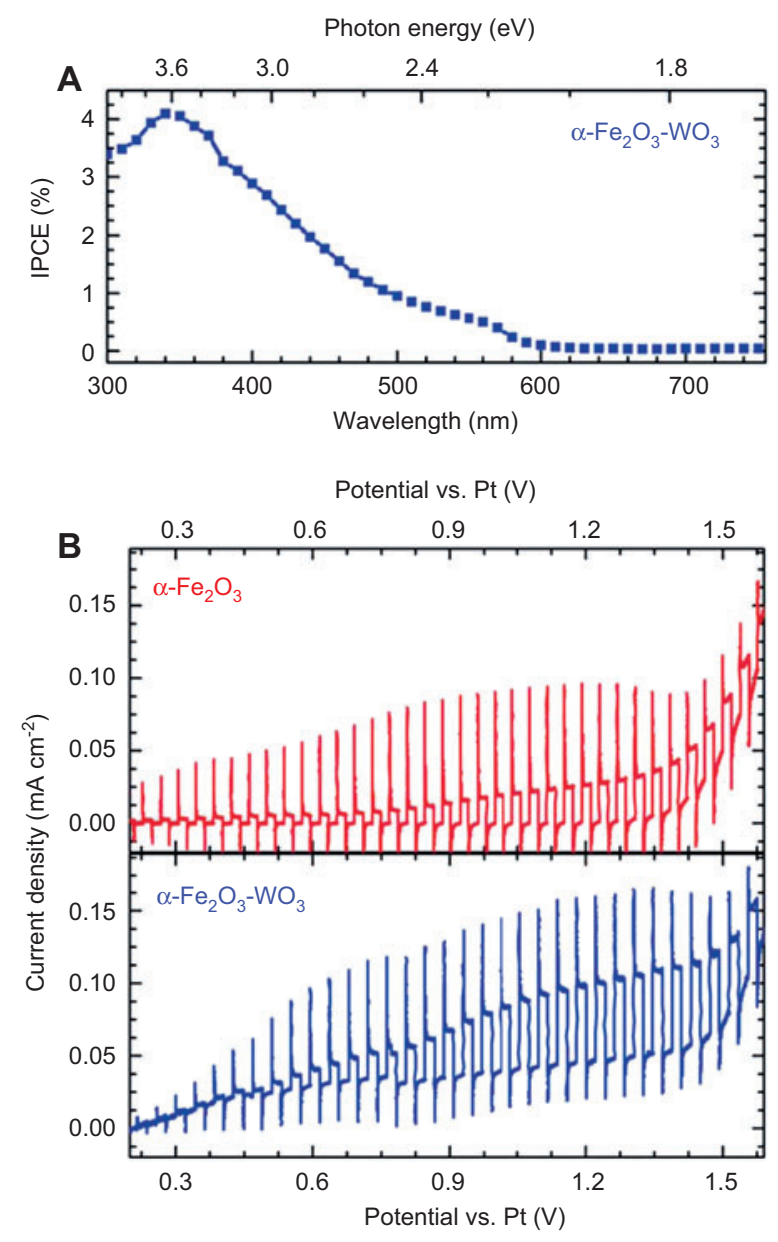

Figure 9 Photoelectrochemical characterization in aqueous $0.5 \mathrm{M}$ $\mathrm{NaCl}$ solution: (A) IPCE spectrum with $+1 \mathrm{~V}$ applied vs. a Pt counter electrode. (B) Photocurrent-potential curve under chopped $\left(0.2 \mathrm{~s}^{-1}\right)$, $100 \mathrm{~mW} \mathrm{~cm}^{-2}$ AM 1.5 G-filtered solar-simulated irradiation. Potential applied vs. a Pt counter electrode. Reprinted with permission from ref. [57]. Copyright 2011 Royal Society of Chemistry.

$\mathrm{TiO}_{2}$-core/ $\mathrm{WO}_{3}$-shell structures had a distinct photoresponse in the UV range, with wavelength $\lambda<400 \mathrm{~nm}$, while the $\mathrm{WO}_{3}$-core/ $/ \mathrm{TiO}_{2}$-shell structures showed stronger visible light absorption and photocurrent up to $\lambda \sim 600 \mathrm{~nm}$. These core-shell nanorod structures, which preserved the optical properties and water splitting performance of the core while the surface properties such as the flat band potential of the nanorods were modified by the shell, could take advantage of the beneficial optical, chemical, and transport properties of both materials. Recently, Mao and his team designed a novel isostructural $\mathrm{ZnO}: \mathrm{Al} / \mathrm{ZnO}: \mathrm{Ni}$ core/shell nanorod structure for photoelectrochemical water splitting, following the concept demonstrated with $\mathrm{ZnO}$ nanorods doped in core regions with shallow Al donor levels for enhanced electronic conduction and in the near-surface volume with intragap Ni impurity states for increased optical absorption [61]. As shown in Figure 10A, approximately a three-fold enhancement in conversion efficiencies for solar-abundant visible wavelengths was achieved over a $\mathrm{ZnO}: \mathrm{Al} / \mathrm{ZnO}: \mathrm{Ni}$ core/shell structure by 

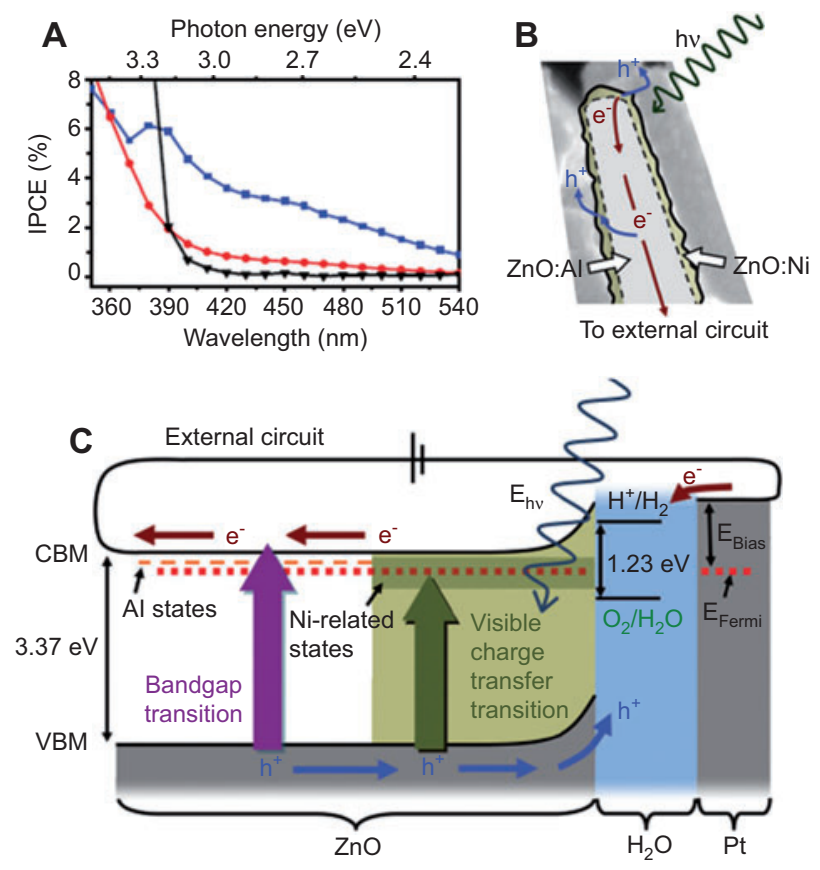

Figure 10 (A) Incident photon conversion efficiency at visible wavelengths for $\mathrm{ZnO}: \mathrm{Al} / \mathrm{ZnO}: \mathrm{Ni}$ homojunction array (blue squares), $\mathrm{ZnO}$ :Ni thin film (red circles), and $\mathrm{ZnO}$ :Al nanorod array (black triangles), with $+1 \mathrm{~V}$ applied vs. a Pt counter electrode. (B) A schematic of idealized operating mechanisms overlayed onto the tip of an individual nanostructure. (C) Idealized energetics of the functional homojunction nanostructure. Reprinted with permission from ref. [61]. Copyright 2012 WILEY-VCH.

distributing the absorptive species normal to the substrate and along the direction of light propagation. The proposed operating mechanisms and band diagram within the core/shell structure were established in Figure 10B and C.

Fabrication of tunnel junctions with a thin overlay of wide band gap oxide such as $\mathrm{MgO}$ and $\mathrm{Al}_{2} \mathrm{O}_{3}$ has been explored as an effective method to inhibit the back electron transfer reaction in dye sensitized solar cells $[62,63]$. A series of $\mathrm{MgO} /$ $\mathrm{TiO}_{2}$ structures with varying effective thickness of $\mathrm{MgO}$ was fabricated and applied by Bae et al. [64] as working electrodes for photoelectrochemical water splitting. The $\mathrm{MgO}$ tunnel layer had two roles with regard to the water splitting performance: (1) blocking the back electron transfer from $\mathrm{TiO}_{2}$ to electrolyte (positive influence) and (2) blocking the hole transfer from $\mathrm{TiO}_{2}$ to electrolyte (negative influence). Thus, the competition between the positive and negative influences of the $\mathrm{MgO}$ layer resulted in maximal performance of the photoelectrochemical cell at an optimum effective thickness of the $\mathrm{MgO}$ overcoating layer. However, under a bias voltage, the negative influence prevailed over the positive influence; thereby the increase of $\mathrm{MgO}$ thickness diminished the photoelectrochemical performance. Guo et al. [65] fabricated a novel $\mathrm{MgO} / \mathrm{TiO}_{2}$ tunnel barrier photoelectrode for solar water splitting. The thin $\mathrm{MgO}$ tunnel barrier on the surface of $\mathrm{TiO}_{2}$ electrode was supposed to isolate the semiconductor electrode from the electrolyte and prevents the electrode from experiencing photocorrosion. Although the photocurrent was attenuated by the presence of the tunnel barrier, reasonable levels of charge transport across the interface were still allowed. These results indicated that tunnel barrier photoelectrodes with the light absorption of semiconductors which matched well with the solar spectrum might be a route to efficient and stable water splitting.

Although $\alpha-\mathrm{Fe}_{2} \mathrm{O}_{3}$ has been considered as a promising photoanode material for photoelectrochemical solar water splitting, the high overpotential for water oxidation, as a result of surface trapping states, greatly limits its photoelectrochemical performance. Grätzel et al. demonstrated that the photocurrent onset potential for solar water oxidation with photoanodes could be improved by the deposition of a 13-group oxide $\left(\mathrm{Al}_{2} \mathrm{O}_{3}, \mathrm{Ga}_{2} \mathrm{O}_{3}\right.$, or $\left.\mathrm{In}_{2} \mathrm{O}_{3}\right)$ thin overlayer [66-68]. They found that an ultra-thin coating of the $\mathrm{Al}_{2} \mathrm{O}_{3}$ overlayer by atomic layer deposition (ALD) reduced the overpotential required with nanostructured $\alpha-\mathrm{Fe}_{2} \mathrm{O}_{3}$ photoanodes by as much as 100 $\mathrm{mV}$ and increased the photocurrent by a factor of 3.5 at +1.0 $\mathrm{V}$ vs. RHE under standard illumination conditions [66]. A detailed investigation into the effect of the $\mathrm{Al}_{2} \mathrm{O}_{3}$ overlayer revealed a significant change in the surface capacitance and radiative recombination, which distinguished the observed overpotential reduction from a catalytic effect and confirmed the passivation of surface states. Instead of ALD, which relies on reactive and expensive metalorganic compounds and vacuum processing, Hisatomi et al. [67] modified the ultrathin $\alpha-\mathrm{Fe}_{2} \mathrm{O}_{3}$ photoanodes with $\mathrm{Al}_{2} \mathrm{O}_{3}, \mathrm{Ga}_{2} \mathrm{O}_{3}$, or $\mathrm{In}_{2} \mathrm{O}_{3}$ overlayer by a facile chemical bath deposition (CBD) process based on a urea hydrolysis method. It was proposed that the 13-group oxide overlayers with the corundum structure released lattice strain of the ultrathin $\alpha-\mathrm{Fe}_{2} \mathrm{O}_{3}$ layer and decreased the density of surface states. Particularly, a $\mathrm{Ga}_{2} \mathrm{O}_{3}$ overlayer improved the onset potential of photoelectrochemical water oxidation on ultrathin $\alpha-\mathrm{Fe}_{2} \mathrm{O}_{3}$ by up to $200 \mathrm{mV}$. They also investigated the effects of $\mathrm{In}_{2} \mathrm{O}_{3}$ deposition on the $\mathrm{LaTiO}_{2} \mathrm{~N}$ electrodes using sputtering at room temperature [68]. Deposition of an $\operatorname{In}_{2} \mathrm{O}_{3}$ overlayer multiplied photocurrents by a factor of $2-3$, which could be attributed to better charge separation due to appreciate band positions of the materials involved, as well as better charge extraction by the action of a surface dipole.

\section{Novel nanostructured heterojunctions}

\subsection{Plasmonic metal/semiconductor nanostructures}

Since the conception of plasmonic photocatalysis was proposed $[69,70]$, plasmonic metal/semiconductor nanostructures, characterized by their strong interaction with resonant photons through an excitation of localized surface plasmon resonance (LSPR), have received significant attention in the fields of photocatalytic pollutant degradation [71-74], selective reduction and oxidation [75-79], cell killing [80], as well as water splitting $[81,82]$. It has been demonstrated that plasmonic metal/ semiconductor nanostructures always achieved significantly higher rates in various photocatalytic reactions compared to their pure semiconductor counterparts, due to the plasmonic 
effects of noble metal nanoparticles, which could give rise to enhancement in light absorption and charge separation [82]. The physical principles of plasmonic effects and phenomenon have been comprehensively described in many review articles [83-86]. Here we focus on the recent progress in plasmon-enhanced water splitting systems, which are in general the nanocomposites of semiconductors and plasmonic-metals (mainly $\mathrm{Ag}$ and $\mathrm{Au}$ ) acting as photocatalysts or photoelectrodes.

Noble metal nanoparticles such as $\mathrm{Au}$ and $\mathrm{Ag}$ have been used to enhance the visible light photocatalytic activity of $\mathrm{TiO}_{2}$ which only absorbs UV light, because of their plasmonic properties $[87,88]$. Thus, both photon energies of UV and visible light can be absorbed by $\mathrm{TiO}_{2}$ to produce hydrogen via water splitting. The enhancement of photocatalytic or photoelectrochemical water splitting by integrating strongly plasmonic $\mathrm{Au}$ nanoparticles with $\mathrm{TiO}_{2}$ has been demonstrated by different research groups [89-93]. Chen et al. [91] found that the photocatalytic activity for stoichiometric hydrogen and oxygen production over $\mathrm{Au} / \mathrm{TiO}_{2}$ under the irradiation of both $\mathrm{UV}$ and visible light was significantly increased, because Au particles not only acted as electron traps as well as active sites but also played an important role in the plasmonic enhancement. Liu et al. [92] also observed enhancements of up to 66 times in the photocatalytic splitting of water on $\mathrm{TiO}_{2}$ with the addition of Au nanoparticles under visible light irradiation, whereas a 4-fold reduction in the photocatalytic activity under UV irradiation was observed. Thus, the improvement of photocatalytic activity in the visible range was deductively caused by the local electric field enhancement near the $\mathrm{TiO}_{2}$ surface, rather than the direct charge transfer between $\mathrm{Au}$ and $\mathrm{TiO}_{2}$. Recently, the influence of excitation wavelength (UV or visible light) on the photocatalytic activity of $\mathrm{Au} / \mathrm{TiO}_{2}$ for hydrogen or oxygen generation from water was investigated by Silva et al. [94]. They revealed that the efficiency and operating mechanism were different depending on whether excitation occurred on the $\mathrm{TiO}_{2}$ semiconductor (Au acting as electron buffer and site for gas generation, shown in Figure 11A) or on the surface plasmon band of $\mathrm{Au}$ (photoinjection of electrons from $\mathrm{Au}$ to the $\mathrm{TiO}_{2}$ conduction band, shown in Figure 11B and C). Moreover, the Au particle size and calcination temperature played a certain role influencing the visible light photoactivity of $\mathrm{Au} / \mathrm{TiO}_{2}$. $\mathrm{Ag}$ nanoparticles also show efficient plasmon resonance in the visible region, and it has been utilized to develop plasmonic $\mathrm{Ag} / \mathrm{TiO}_{2}$ nanostructures for solar water splitting [95-97]. For example, $\mathrm{Ag} / \mathrm{TiO}_{2}$ core/shell nanoparticle thin film was fabricated for photoelectrochemical water splitting in the visible light region, and showed enhancement of positive photocurrent because of the generation of photoelectrons resulted from the surface plasmon resonance of Ag cores [97]. Ingram and Linic [98] demonstrated that plasmonic $\mathrm{Ag} / \mathrm{N}-\mathrm{TiO}_{2}$ nanostructure exhibited enhanced water splitting performance relative to the $\mathrm{N}-\mathrm{TiO}_{2}$ semiconductor alone, which could be attributed to the formation of intense electric fields at the $\mathrm{Ag}$ particle surface, increasing the rate of formation of electron-hole pairs at the nearby $\mathrm{N}-\mathrm{TiO}_{2}$ particle surface. The efficient plasmonic metal/ semiconductor photocatalysts can be further flexibly designed by tuning the size and shape of plasmonic metal nanoparticles and thereby controlling the energy and intensity of the LSPR.

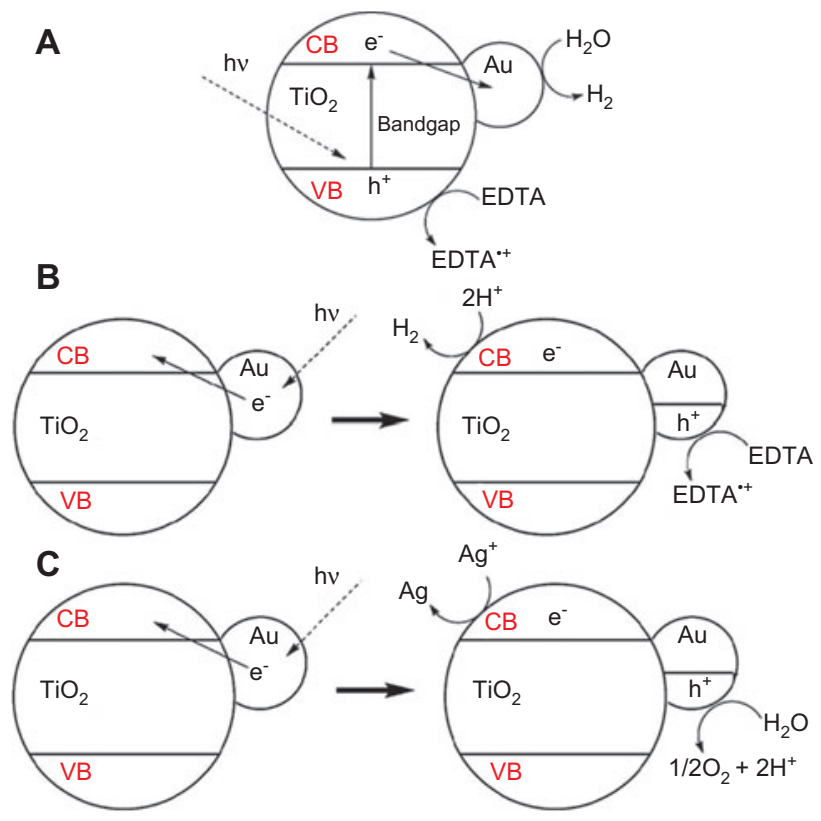

Figure 11 Proposed rationalization of the photocatalytic activity of $\mathrm{Au} / \mathrm{TiO}_{2}$ (A) under UV light excitation, (B) forming $\mathrm{H}_{2}$ and (C) forming $\mathrm{O}_{2}$ upon excitation of the gold surface plasmon band. Reprinted with permission from ref. [94]. Copyright 2011 American Chemical Society.

The influence of $\mathrm{Au}$ nanoparticles on $\alpha-\mathrm{Fe}_{2} \mathrm{O}_{3}$ photoanodes for photoelectrochemical water splitting was investigated by Thimsen et al. [99]. A relative enhancement in the water splitting efficiency at photon frequencies corresponding to the plasmon resonance in $\mathrm{Au}$ was observed when $\mathrm{Au}$ nanoparticles were localized at the semiconductor-electrolyte interface, because of the coupling between the localized surface plasmon and semiconductor. In Thomann's systematic investigation on the plasmon enhanced photoelectrochemical water splitting over $\mathrm{Au} / \alpha-\mathrm{Fe}_{2} \mathrm{O}_{3}$ photoanodes, they claimed that metallic nanostructures could enhance the photocurrent in spectral regions near the surface plasmon resonance, and the spectral dependence of the photocurrent spectra was characteristic of plasmonic structures, as shown in Figure 12 [100]. Thus, the effects of different types of metallic nanostructures and different placement of such particles with respect to the photoelectrode materials on the photocurrent spectra could be predicted according to the plasmonic effects. While $\mathrm{CeO}_{2}$ was loaded with $\mathrm{Au}$ nanoparticles, the photocatalytic activity under visible light irradiation was greatly enhanced; moreover, the ability to generate $\mathrm{O}_{2}$ was found to follow the surface plasmon band profile of Au nanoparticles [101]. This supported that $\mathrm{Au}$ nanoparticles were the species responsible for light absorption in $\mathrm{Au} / \mathrm{CeO}_{2}$ and triggered the photochemical events, as illustrated in Figure 11C.

\subsection{Z-scheme heterojunctions}

The two-photoexcited photocatalysis (Z-scheme) system mimicked with photosynthesis mechanism was investigated 
A
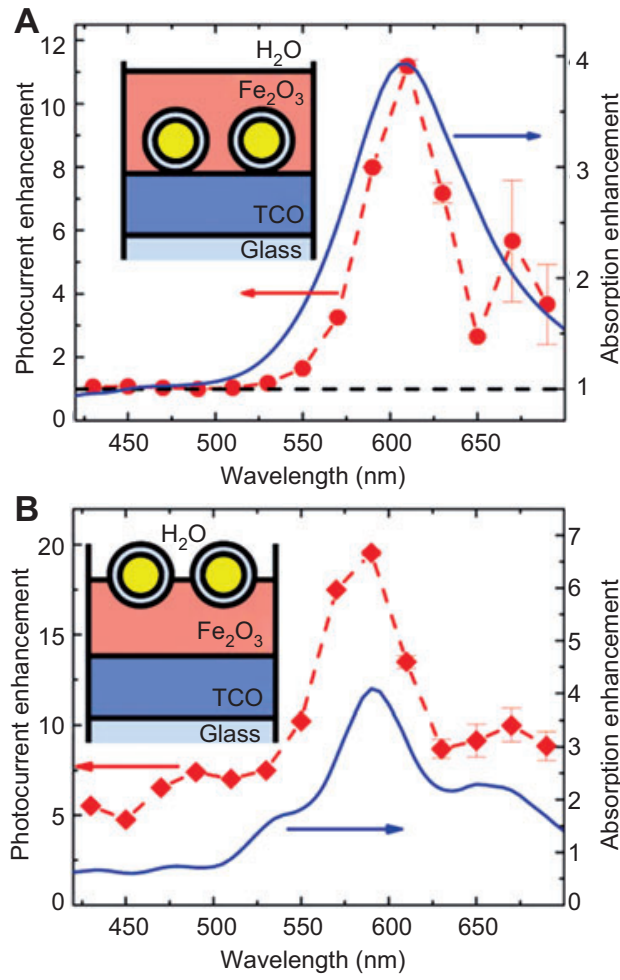
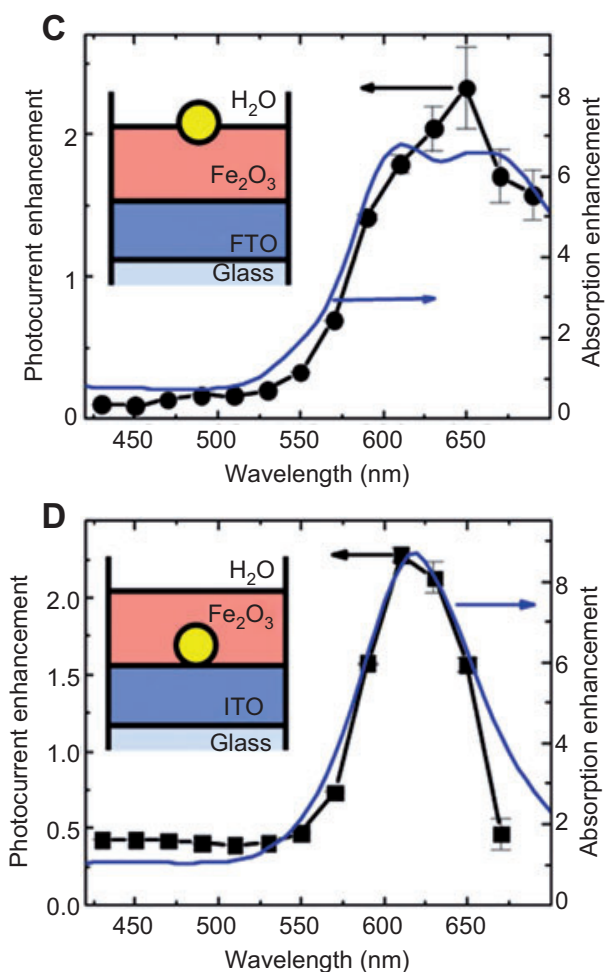

Figure 12 (A,B) Photocurrent enhancement spectra for Au nanoparticles with a silica shell. Measured photocurrent (red symbols) and simulated (solid blue lines) absorption enhancement spectra that show the beneficial effects of placing silica-coated Au particles at the bottom/on top of a $100 \mathrm{~nm}$ thin $\mathrm{Fe}_{2} \mathrm{O}_{3}$ photoelectrode layer. Both samples exhibit strong ( $>10 \mathrm{x}$ ) enhancement over a relatively broad wavelength range. Electromagnetic simulations (blue lines) are consistent with a plasmonic origin of the observed enhancements in the $550-650 \mathrm{~nm}$ wavelength range. (C,D) Plasmonic effects in the photocurrent enhancement spectra obtained with bare Au nanoparticles. Measured photocurrent enhancement spectra (black symbols) exhibit one dominant spectral feature and are well explained by plasmonic effects (electromagnetic simulations, blue lines). In contrast to core shell particles, bare gold particles often show reduced photocurrents compared to simulation results, possibly due to undesired charge recombination. It is important to note that the samples with Au particles on top of the $\mathrm{Fe}_{2} \mathrm{O}_{3}$ produce asymmetric photocurrent enhancement spectra, whereas the samples with particles at the bottom of the $\mathrm{Fe}_{2} \mathrm{O}_{3}$ film produce symmetric peaks. This observed behavior is a signature of plasmonic effects. Reprinted with permission from ref. [100]. Copyright 2011 American Chemical Society.

in order to produce $\mathrm{H}_{2}$ and $\mathrm{O}_{2}$ from water using solar energy [7, 102]. Figure 13 shows a Z-scheme photocatalysis system composed of a $\mathrm{H}_{2}$-evolving photocatalyst $\mathrm{Pt} / \mathrm{SrTiO}_{3}: \mathrm{Rh}$, an $\mathrm{O}_{2}$-evolving photocatalyst $\mathrm{BiVO}_{4}$, and an electron mediator $\mathrm{Fe}^{3+} / \mathrm{Fe}^{2+}$ [103]. Overall water splitting has been attained by constructing a Z-scheme photocatalysis system using photocatalysts active only for half reactions of water splitting (sacrificial $\mathrm{H}_{2}$ and $\mathrm{O}_{2}$ evolution reactions) in the absence of sacrificial reagents. In general, a redox mediator (such as $\mathrm{IO}_{3}^{-}$ /I- or $\left.\mathrm{Fe}^{3+} / \mathrm{Fe}^{2+}\right)$ is required to couple with two photosystems. However, the electron mediator involving in undesirable backward reactions also produces negative effects, as illustrated in Figure 13 [102, 103]. Therefore, a Z-scheme system without an electron mediator, i.e., all-solid-state Z-scheme photocatalyst, has attracted much attention in retarding back reactions to increase the reaction efficiency.

A number of all-solid-state Z-scheme photocatalysts, such as CdS-Au-TiO 2 [104], AgBr-Ag- $\mathrm{Bi}_{2} \mathrm{WO}_{6}$ [105], AgBr-Ag$\mathrm{TiO}_{2}$ [106], $\mathrm{H}_{2} \mathrm{WO}_{4} / \mathrm{Ag} / \mathrm{AgCl}$ [107], etc., has been demonstrated to exhibit a high photocatalytic activity, far exceeding those of the single-component systems. In all these multi-component Z-scheme photocatalyst systems, without exception, the separation of photoexcited electron-hole pairs are promoted within the two semiconductors, and further improved by the coupled metal as the electron-transfer mediator. Taking $\mathrm{CdS}-\mathrm{Au}-\mathrm{TiO}_{2}$ as the example as shown in Figure 14, through

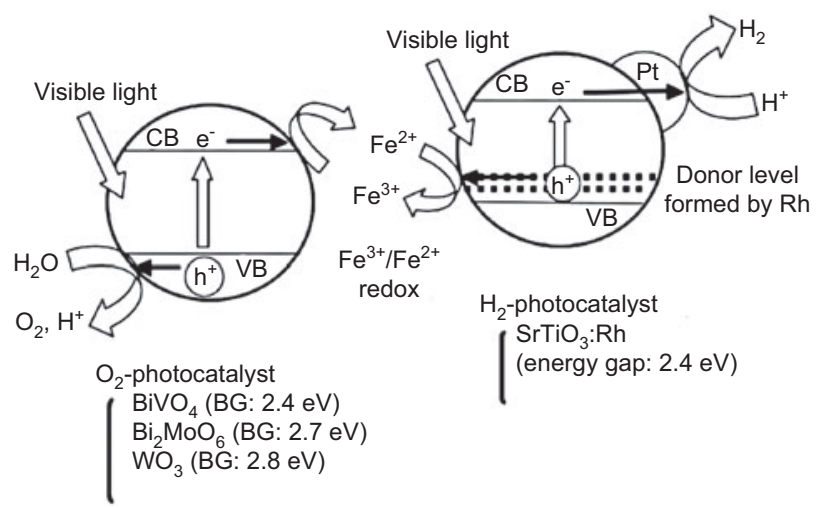

Figure 13 Mechanism of overall water splitting using a Z-scheme photocatalysis system. CB, conduction band; VB, valence band. Reprinted with permission from ref. [103]. Copyright 2008 Elsevier. 


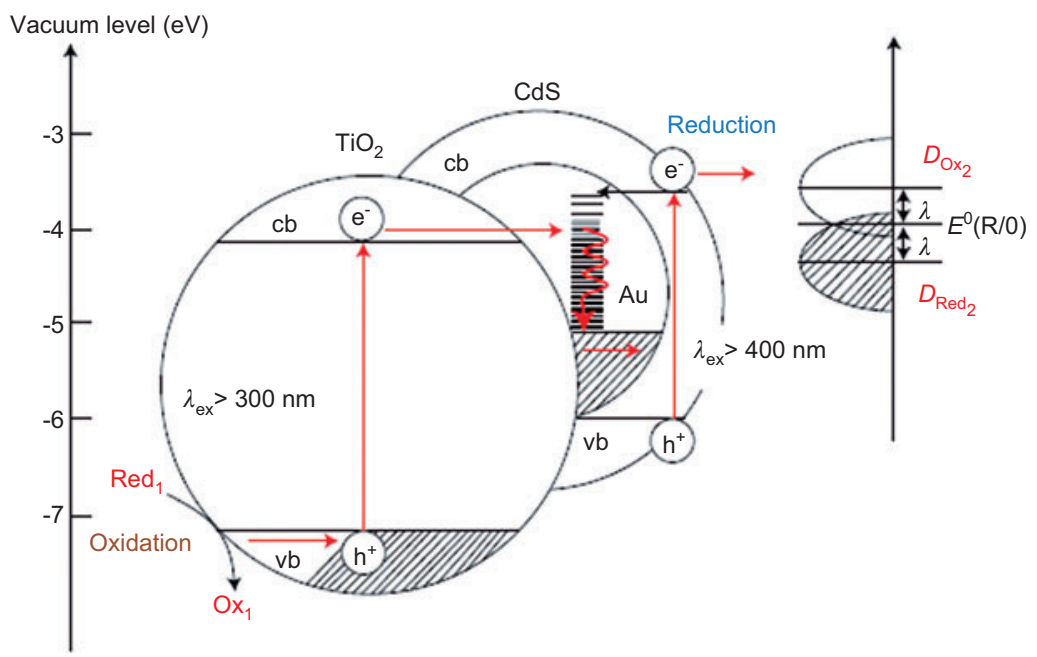

Figure 14 Energy band diagram scheme of the $\mathrm{CdS}-\mathrm{Au}-\mathrm{TiO}_{2}$ system. $E^{0}(\mathrm{R} / \mathrm{O})$ is the standard electrode potential of $\mathrm{MV}^{+} / \mathrm{MV}^{2+} . D_{\mathrm{Red}}$ and $D_{\mathrm{Ox}_{2}}$ represent the distribution function for occupied and unoccupied states, respectively, and $\lambda$ is the reorganization energy. Reprinted with permission from ref. [104]. Copyright 2006 Nature Publishing Group.

a two-step excitation of $\mathrm{CdS}, \mathrm{TiO}_{2}$ and with $\mathrm{Au}$ as an electrontransfer mediator, photoinduced electrons achieved a vectorial transfer of $\mathrm{TiO}_{2} \rightarrow \mathrm{Au} \rightarrow \mathrm{CdS}$, which led to the promoted charge separation and hence improved photocatalytic activity in such three-component system [104].

The Z-scheme electron-transfer mechanism occurring within two intimately contacted semiconductors has also been proved to be very successful in designing all-solid-state Z-scheme photocatalysts for enhanced water splitting. Wang et al. [108, 109] fabricated coupled $\mathrm{ZnO} / \mathrm{CdS}$ heterostructures based on the Z-scheme mechanism, where the recombination of photoexcited electrons from the $\mathrm{ZnO}$ conduction band and holes from the CdS valence band occurs at the interface. The synergistic effects of coupled $\mathrm{ZnO} / \mathrm{CdS} \mathrm{Z}$-scheme heterostructures on the enhancement of photocatalytic water splitting should be related to the greatly prolonged lifetime of photoexcited carriers. In a further study, they developed a new type of heterostructure by introducing a metal $\mathrm{Cd}$ core into a $\mathrm{ZnO} / \mathrm{CdS}$ heterostructure [110]. The obtained $\mathrm{ZnO} / \mathrm{Cd} /$ $\mathrm{CdS}$ exhibited a greatly enhanced photocatalytic hydrogen evolution rate, which was 5.1 times that of a $\mathrm{ZnO} / \mathrm{CdS}$ heterostructure. This was because the metal $\mathrm{Cd}$ core provided an efficient charge-carrier transport channel at the interface of $\mathrm{ZnO} / \mathrm{CdS}$ for improving the recombination of photoexcited electrons from $\mathrm{ZnO}$ and holes from $\mathrm{CdS}$ based on the Z-scheme co-operation (Figure 15).

A similar Z-scheme electron/hole transport mechanism was proposed to occur on the interface of highly active CdS sensitized $\mathrm{TiO}_{2}$ photoanodes for solar water splitting [111]. While combining two visible light sensitive photocatalysts, $\mathrm{CdS}$ and carbon-doped $\mathrm{TiO}_{2}$, with $\mathrm{Au}$ as the electron-transfer mediator, the combination of $\mathrm{CdS} / \mathrm{Au} / \mathrm{TiO}_{1.96} \mathrm{C}_{0.04}$, enabling the successful transfer of photogenerated electrons to a higher energy level via the Z-scheme mechanism, produced approximately a four times higher amount of $\mathrm{H}_{2}$ under visible light irradiation than $\mathrm{CdS} / \mathrm{Au} / \mathrm{TiO}_{2}$ [112]. Fu et al. [113] developed a novel photocatalytic system $\left(\mathrm{TiO}_{2}\right.$-heteropoly blue) capable of utilizing two light beams including UV and visible light to complete the Z-scheme process. This Z-scheme photocatalyst system demonstrated higher stability, higher effectiveness in separating electron-hole pairs, and greater photoactivity for $\mathrm{H}_{2}$ production than a single component system. Such improvement was attributed to the directional electron transfer driven by the photoexcitation of $\mathrm{TiO}_{2}$ and heteropoly blue under the irradiation of UV and visible light, respectively.

Recently, Sasaki et al. [114] succeeded in constructing an overall water splitting system $\left(\mathrm{Ru} / \mathrm{SrTiO}_{3}: \mathrm{Rh}-\mathrm{BiVO}_{4}\right)$ driven by a Z-scheme interparticle electron transfer between $\mathrm{H}_{2}$ and $\mathrm{O}_{2}$-photocatalysts without a redox mediator. As shown in Figure 16A, the interparticle electron transfer process required $\mathrm{Rh}$ species with the reversibility of the oxidation state in $\mathrm{SrTiO}_{3}: \mathrm{Rh}$, indicating that the reversible $\mathrm{Rh}$ species at the surface of $\mathrm{SrTiO}_{3}: \mathrm{Rh}_{2}$-photocatalyst played a pivotal role for the electron transfer between particles to complete the Z-scheme process. However, the direct contact between photocatalyst particles would not still be sufficient for electron transfer, and thus the electron transfer process between photocatalyst particles is probably a rate-determining step on

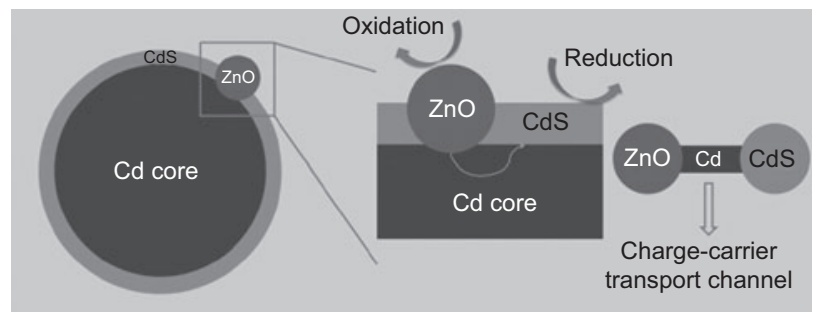

Figure 15 Scheme of the improving mechanism of photoexcited charge-carrier transport in the $\mathrm{ZnO} / \mathrm{Cd} / \mathrm{CdS}$ heterostructure. Reprinted with permission from ref. [110]. Copyright 2012 WILEY$\mathrm{VCH}$. 
A

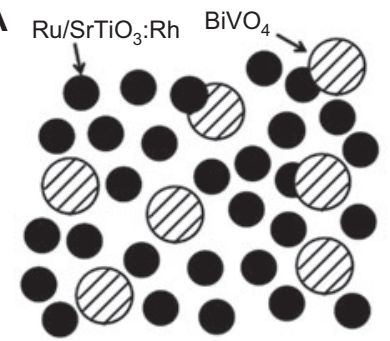

Neutral pH conditions

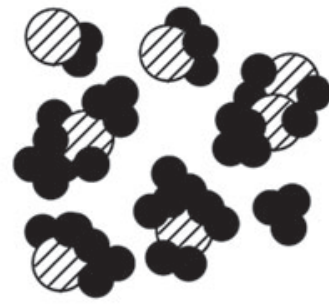

Acidic conditions
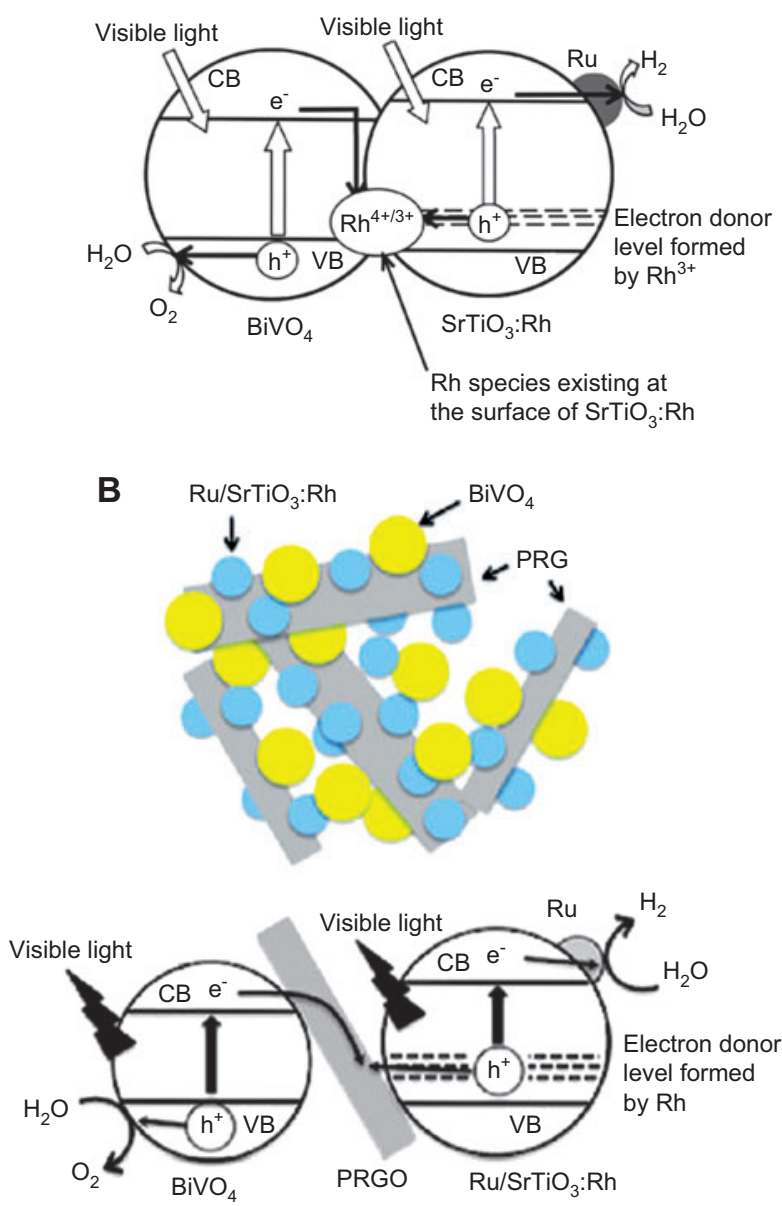

Figure 16 Mechanism of water splitting in a Z-scheme photocatalysis system consisting of (A) $\mathrm{Ru} / \mathrm{SrTiO}_{3}: \mathrm{Rh}$ and $\mathrm{BiVO}_{4}$. Reprinted with permission from ref. [114]. Copyright 2009 American Chemical Society. (B) $\mathrm{Ru} / \mathrm{SrTiO}_{3}: \mathrm{Rh}$ and $\mathrm{PRGO} / \mathrm{BiVO}_{4}$ under visible-light irradiation. Reprinted with permission from ref. [115]. Copyright 2011 American Chemical Society.

the photocatalytic reaction in this Z-scheme system. In the follow-up study, Iwase et al. [115] demonstrated the effectiveness of reduced graphene oxide as a solid electron mediator for water splitting in the Z-scheme photocatalysis system. As shown in Figure 16B, a tailor-made, photoreduced graphene oxide (PRGO) could shuttle photogenerated electrons from an $\mathrm{O}_{2}$-evolving photocatalyst $\left(\mathrm{BiVO}_{4}\right)$ to a $\mathrm{H}_{2}$-evolving photocatalyst $\left(\mathrm{Ru} / \mathrm{SrTiO}_{3}: \mathrm{Rh}\right)$, tripling the consumption of electron-hole pairs in the overall water splitting reaction under visible-light irradiation, and hence providing a great improvement in the activity for water splitting.

\section{Photonic crystals}

In addition to some well-known chemical modifications, such as ion doping, semiconductor combination, and dye sensitization, etc., to make better use of the full solar spectrum, physical modification like photonic-crystal-based optical coupling [116] offers a unique way to increase light harvesting by controlling the propagation of light and localization of photons. Since the first report of using $\mathrm{TiO}_{2}$ inverse opal as a photoanode by Mallouk's team [117], $\mathrm{TiO}_{2}$ inverse opal based photonic crystal has been frequently reported as a photoanode in dye-sensitized solar cells to enhance light harvesting [118-121]. It was demonstrated by Chen et al. [122-124] that an amplified photochemical reaction on an inverse $\mathrm{TiO}_{2}$ colloidal based photonic crystal, which was related to the enhanced interaction of light with photoresponsive semiconductors, could be explained as a slow photon effect. Based on this unique effect, it has been of great scientific interest to tailor semiconducting photonic crystals as efficient photocatalyts used for degradation of organic pollutant [125-131]. This slow photon effect can also benefit the reaction of solar water splitting based on semiconductor photocatalysts and photoelectrodes. This section will briefly introduce the recent progress in using tailored semiconducting photonic crystals as a light trapper to strengthen solar light absorption for enhanced conversion efficiency of solar water splitting.

Liu et al. designed and structured $\mathrm{TiO}_{2}$ materials into hierarchical photonic crystal segments with stop bands overlapping with the absorption of $\mathrm{TiO}_{2}$ [132]. It was demonstrated that the hierarchical $\mathrm{TiO}_{2}$ photonic crystal segments showed great capabilities in strong light harvesting due to the slow photon enhancement at the stop band edge and multiple scattering among the segments. Therefore, the promoted light absorption of $\mathrm{TiO}_{2}$ with photonic crystal structures led to more photogenerated electron-hole pairs and consequently higher photocatalytic hydrogen evolution rates relative to nanocrystalline $\mathrm{TiO}_{2}$. Expect for the slow photon effect to enhance light absorption, the highly ordered and periodical three-dimensional (3D) inverse opal structure of photonic crystals offered very high specific surface area and porosity for quantum-dot (QD) loading plus a good electron transport path and intimate contact with the electrolyte. Cheng et al. [133] reported an innovative electrode design by the combination of a $\mathrm{TiO}_{2}$ inverse opal with CdS QD sensitization for photoelectrochemical hydrogen production. Figure 17 shows the fabrication procedure of the 3D QD-sensitized $\mathrm{TiO}_{2}$ inverse-opal photoanode. While the QDs acting as "light antennas" greatly improved the visible-light harvesting, the band alignment between $\mathrm{CdS}$ and $\mathrm{TiO}_{2}$ also favored interfacial charge transfer and separation. Moreover, the photonic bandgap feature facilitated photon-QD interaction, as a result of enhanced light absorption. A promising photocurrent density of $4.84 \mathrm{~mA} \cdot \mathrm{cm}^{-2}$ was achieved for the CdS QD sensitized $\mathrm{TiO}_{2}$ inverse opal as photoanode at $0 \mathrm{~V}$ vs. $\mathrm{Ag} / \mathrm{AgCl}$ 


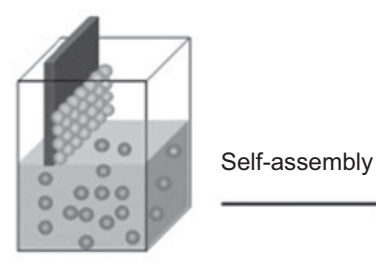

A

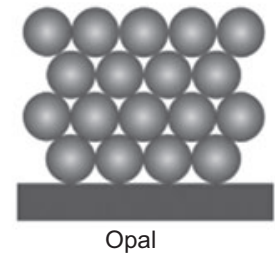

B

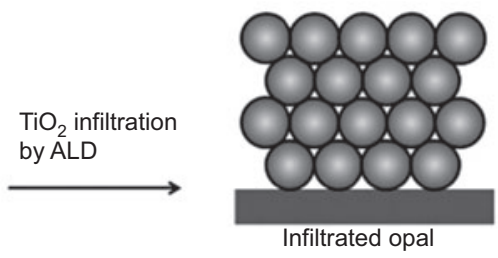

C

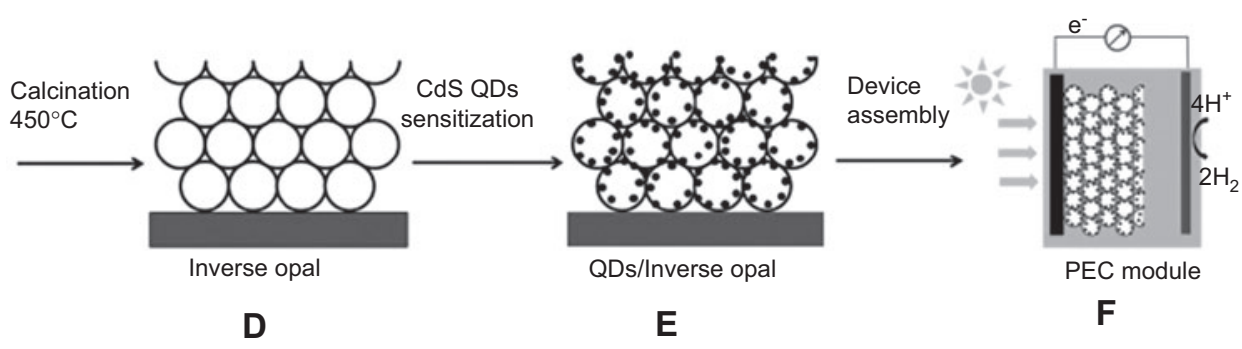

Figure 17 Schematic of the fabrication procedure of the 3D QD-sensitized $\mathrm{TiO}_{2}$ inverse-opal photoanode. Reprinted with permission from ref. [133]. Copyright 2012 WILEY-VCH.

under simulated solar-light illumination. On the other hand, significant enhancement in photoelectrochemical performances was also observed at $\mathrm{CdS}$ QDs sensitized $\mathrm{TiO}_{2}$ films with highly disordered inverse opal structure, which were fabricated by replicating a template from 150, 190 to $243 \mathrm{~nm}$ diameter polystyrene spheres [134]. This should be ascribed to slowed light resulting from the interference of multiple internal scattering events in the disordered photonic crystal medium. As shown in Figure 18, depending on the degree of disorder in a medium, multiple elastic scattering can lead to light localization by interference of counter-propagating waves, leading to significant enhancements in light harvesting. This effect would contribute to the observed gains at the disordered inverse opals, and mostly exist where absorption is low $[118,134]$.

3D-photonic crystal design was utilized to enhance photoactivities of some other metal oxide photoanodes. Inverse opal $\mathrm{WO}_{3}$ photonic crystal photoanodes with different stopbands tuned experimentally by variation of the pore size of inverse opal structures, as shown in Figure 19A-E, were prepared by a forced impregnation approach $[135,136]$. It was found from Figure 19E-F that when the red-edge of the photonic stop-band of $\mathrm{WO}_{3}$ inverse opals ( $\left.\mathrm{WO}_{3}-260\right)$ overlapped with the $\mathrm{WO}_{3}$ electronic absorption edge at $E_{g}=2.6 \sim 2.8 \mathrm{eV}$, a maximum of $100 \%$ increase in photocurrent intensity was observed under visible light irradiation $(\lambda>400 \mathrm{~nm})$ in comparison with a disordered porous $\mathrm{WO}_{3}$ photoanode. When the red-edge of the stop-band was tuned well within the electronic absorption range of $\mathrm{WO}_{3}\left(\mathrm{WO}_{3}-200\right)$, noticeable but less amplitude of enhancement in the photocurrent intensity was observed. The enhancement could be attributed to a longer photon-matter interaction length as a result of the slowlight effect at the photonic stop-band edge, thus leading to a remarkable improvement in the light-harvesting efficiency [136]. $\mathrm{Bi}_{2} \mathrm{WO}_{6}$ inverse-opal photonic-crystal structures, as an example for visible-lightactive ternary metal oxides, were synthesized by Zhang et al. [137] for the first time. $\mathrm{Bi}_{2} \mathrm{WO}_{6}$ inverse opals with a well-crystallized framework exhibited an almost three-fold increase for the photon-to-hydrogen conversion efficiencies of photoelectrochemical water splitting under visible-light irradiation. Such enhancements in the photoelectrochemical $\mathrm{H}_{2}$ production activity were related to the improved light-harvesting properties, as well as the continuous porous structure of the inverse-opal structure. These works provide useful information for developing other visible-light-sensitive photoanodes (like $\alpha-\mathrm{Fe}_{2} \mathrm{O}_{3}$ [138]) with photonic crystal structure, and thus a route to obtain more efficient systems for solar energy conversion.

Typical transparent conducting oxide (TCO) materials, including indium-, fluorine-, or antimony-doped tin oxides,

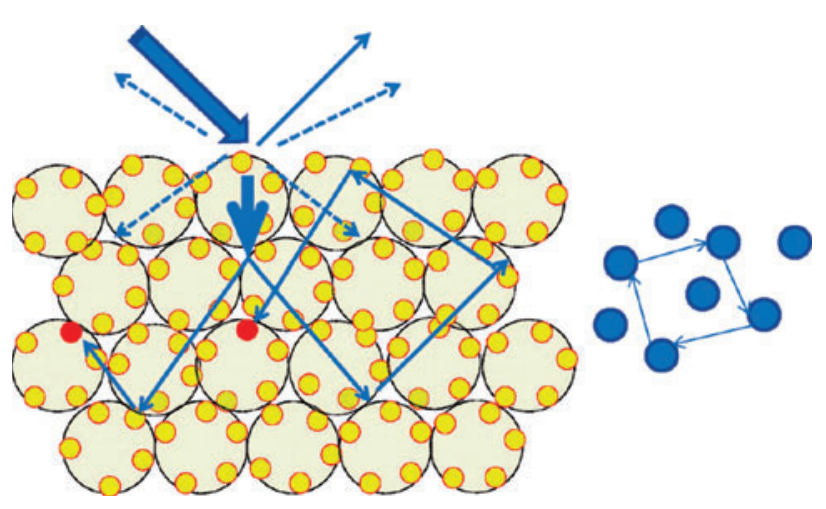

Figure 18 Sketch of a $\mathrm{TiO}_{2}$ inverse opal sensitized with $\mathrm{CdS}$ QD (yellow dots) and processes of Bragg reflection, diffuse scattering, and multiple internal scattering in the photonic crystal. An absorbance event in the inverse opal is denoted by a red dot (not to scale). Right shows a sketch of multiple internal scattering at random scattering centers, leading to light localization. Reprinted with permission from ref. [134]. Copyright 2010 American Chemical Society. 

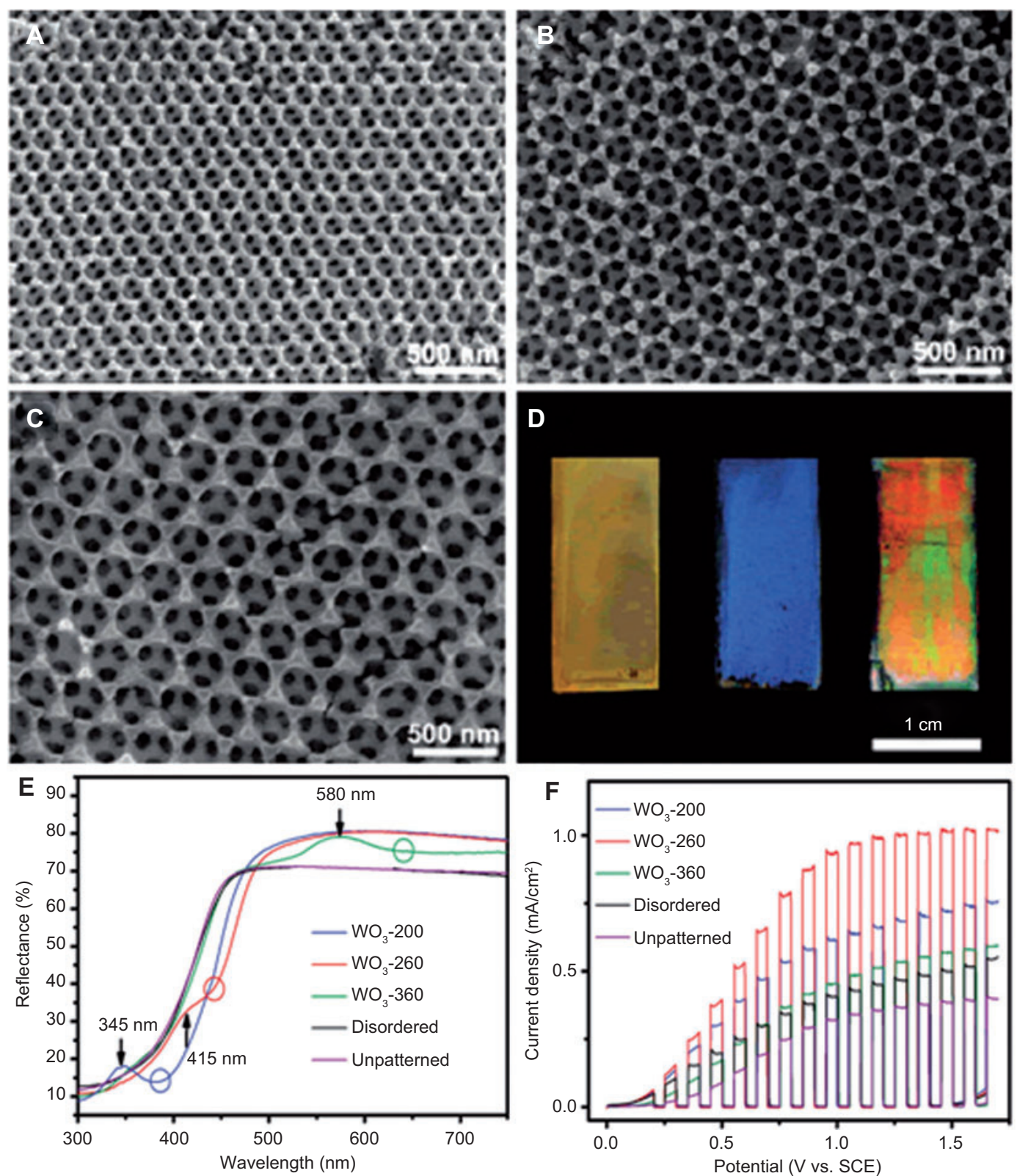

Figure 19 SEM images of $\mathrm{WO}_{3}$ inverse opals: (A) $\mathrm{WO}_{3}-200$, (B) $\mathrm{WO}_{3}-260$, and (C) $\mathrm{WO}_{3}-360$. (D) Photograph of the inverse opal WO photoanodes under white light illumination, $\mathrm{WO}_{3}-200, \mathrm{WO}_{3}-260$, and $\mathrm{WO}_{3}-360$, from left to right. (E) Light reflectance spectra of the $\mathrm{WO}_{3}$ inverse opals, a disordered porous $\mathrm{WO}_{3}$, and an unpatterned $\mathrm{WO}_{3}$ photoanode, measured at a normal incidence of light. Centers of the stop-bands are marked by black arrows. The locations of slow light at the red-edge of stop-band for each inverse opal are shown as colored hollow circles. (F) Photocurrent-potential curves measured under visible light irradiation $(\lambda>400 \mathrm{~nm})$. Reprinted with permission from ref. [136]. Copyright 2011 American Chemical Society.

are the cornerstone of optoelectronic devices, allowing light to transmit with minimal losses while simultaneously transporting charge. Enhancing the charge collection by exploring new architectures in the conventional 2D planar TCO-based electrodes could exploit the full potential of TCOs as electrode materials to meet a multitude of optoelectronic and photoelectrochemical device requirements [139-141]. Arsenault et al. [142] introduced for the first time a periodic macroporous transparent conducting oxide, Sb-doped $\mathrm{SnO}_{2}$, which offered a unique synergistic combination of optical transparency, electrical conductivity, and photonic crystal properties, and presented an electrochemically actuated optical light switch built from this electrode. The ability of this macroporous electrode to host active functional materials like dyes, nanocrystals and nanowires makes it interesting for the development of a number of performance-enhanced photoelectrochemical devices, like dye sensitized solar and water splitting cells. Yang et al. [143] demonstrated the synthesis of highly ordered 3D inverse opal fluorinated tin oxide (FTO) electrodes using a facile, template-based, solution chemistry methodology. 
Synergistically, the photonic crystal structure possessed in the FTO exhibited strong light trapping capability and enhanced charge transport ability. It was proved that the prepared FTO inverse opal structures could be used as photocurrent collecting electrodes in photovoltaic devices with potentially short charge transport distances and enhanced light harvesting due to multiple light scattering in the photonic crystal structures.

\section{Summary and outlook}

In past decades, the main effort of the research on design of photocatalysts and photoelectrodes for efficient solar water splitting has centered on some commonly used approaches such as ion doping, solid solution, etc. to enhance light harvesting, and semiconductor combination, co-catalyst loading, etc. to enhance charge separation and promote surface reaction kinetics [4-8]. Some significant progress has been made and high efficiencies of solar hydrogen conversion have been obtained using, for example, Pt-PdS/CdS [quantum yield (QY) at $420 \mathrm{~nm}: 93 \%$ ] [144], nano-twin CdS-ZnS (QY at $425 \mathrm{~nm}: 43 \%$ ) [145] and $\mathrm{Rh}_{2-\mathrm{x}} \mathrm{Cr}_{\mathrm{x}} \mathrm{O}_{3} / \mathrm{GaN}-\mathrm{ZnO}$ (pure water splitting, QY at $420-440 \mathrm{~nm}: 5.9 \%$ ) [146] as photo-

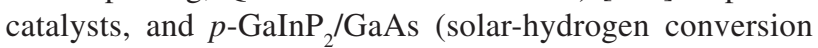
efficiency: $12.4 \%$ ) [147] and $\mathrm{Cu}_{2} \mathrm{O}$ (IPCE: $40 \%$ at $0 \mathrm{~V}$ vs. RHE) [148] as photoelectrodes. While considering the solar hydrogen efficiency, material cost and stability, none of the traditional semiconductor materials is viable for practical application in solar water splitting systems meeting sustainable high-performance ( $>15 \%$ solar-to-hydrogen conversion) and long-term ( $>200 \mathrm{~h}$ life) hydrogen production goals [149].

Essentially, the practical implementation of solar hydrogen production via water splitting is challenged by the rigorous demands that should be achieved by semiconductor solar-active nanostructures simultaneously, those are excellent photon absorption in visible light region, good charge separation/ transport ability, and fast kinetics for surface redox catalytic reaction. Following recent improvements of promising solaractive nanostructures, the novel design concepts are becoming more prominent to address the above challenges and demands of semiconductor-based solar hydrogen production. For example, a breakthrough was obtained on chemically-stable and low-cost $\mathrm{TiO}_{2}$ through the new concept of surface disorder engineering of nanostructures [14]. Such new concepts of solar-active nanostructures design, mainly including surface engineering, novel nanostructured heterojuctions, and photonic crystal fabrication as proposed in this overview, offer the possibility of vast improvements for efficient photocatalysts and photoelectrodes applied in practical solar hydrogen production devices. Although the first results are encouraging, these concepts are primarily laboratory demonstrations at the current stage, and a multitude of basic work must be carried out to characterize the governing behavior in relevant solar water splitting systems. Nevertheless, these new concepts are expected to boost further breakthrough by advanced photon and charge management aiming at high efficiency solar-active nanostructures.
We have provided a concise overview of a subset of the topic: solar-active nanostructures for efficient solar hydrogen production. Considering the realistic implementation of solar hydrogen production via water splitting will require the use of earth-abundant, inexpensive, manufacturable, and non-toxic materials, we suggest that photon absorption, charge separation/transport, and surface reaction kinetic within and on the surface of the nanostructures based on metal oxides such as $\mathrm{TiO}_{2}, \mathrm{ZnO}, \alpha-\mathrm{Fe}_{2} \mathrm{O}_{3}$, and $\mathrm{WO}_{3}$, etc., need significant research attention from the view point of the mentioned new design concepts. In some cases, coupling different concepts (e.g., coupling of plasmonic effect and photonic crystals) could render strong synergistic effects.

\section{Acknowledgement}

This work has been supported by the U.S. Department of Energy, Office of Energy Efficiency and Renewable Energy.

\section{References}

[1] Fujishima A, Honda K. Electrochemical photolysis of water at a semiconductor electrode. Nature 1972;238:37-8.

[2] Bard AJ. Photoelectrochemistry and heterogeneous photocatalysis at semiconductors. J Photochem 1979;10(1):59-75.

[3] Bard AJ. Photoelectrochemistry. Science 1980;207(4427): 139-44.

[4] Kudo A, Miseki Y. Heterogeneous photocatalyst materials for water splitting. Chem Soc Rev 2009;38:253-78.

[5] Maeda K, Domen K. Photocatalytic water splitting: recent progress and future challenges. J Phys Chem Lett 2010;1(18): 2655-61.

[6] Osterloh FE. Inorganic materials as catalysts for photochemical splitting of water. Chem Mater 2008;20(1):35-54.

[7] Chen X, Shen S, Guo L, Mao SS. Semiconductor-based photocatalytic hydrogen generation. Chem Rev 2010;110(11): 6503-70.

[8] Shen S, Shi J, Guo P, Guo L. Visible-light-driven photocatalytic water splitting on nanostructured semiconducting materials. Int J Nanotechnol 2011;8(6-7):523-91.

[9] Sun J, Zhong DK, Gamelin DR. Composite photoanodes for photoelectrochemical solar water splitting. Energy Environ Sci 2010;3:1252-61.

[10] Maeda K, Domen K. Oxynitride materials for solar water splitting. MRS Bulletin 2011;36:25-31.

[11] Zhang JZ. Metal oxide nanomaterials for solar hydrogen generation from photoelectrochemical water splitting. MRS Bulletin 2011;36:48-55.

[12] Tong H, Ouyang S, Bi Y, Umezawa N, Oshikiri M, Ye J. Nanophotocatalytic materials: possibilities and challenges. Adv Mater 2012;24(2):229-51.

[13] Chen X, Mao SS. Titanium dioxide nanomaterials: synthesis, properties, modifications, and applications. Chem Rev 2007;107(7):2891-959.

[14] Chen X, Liu L, Yu PY, Mao SS. Increasing solar absorption for photocatalysis with black hydrogenated titanium dioxide nanocrystals. Science 2011;331(6018):746-50.

[15] Lu J, Dai Y, Jin H, Huang B. Effective increasing of optical absorption and energy conversion efficiency of anatase $\mathrm{TiO}_{2}$ nanocrystals by hydrogenation. Phys Chem Chem Phys 2011;13:18063-68. 
[16] Wang G, Wang H, Ling Y, Tang Y, Yang X, Fitzmorris RC, Wang $\mathrm{C}$, Zhang JZ, Li Y. Hydrogen-treated $\mathrm{TiO}_{2}$ nanowire arrays for photoelectrochemical water splitting. Nano Lett 2011;11(7):3026-33.

[17] Maeda K, Teramura K, Domen K. Development of cocatalysts for photocatalytic overall water splitting on $\left(\mathrm{Ga}_{1-x} \mathrm{Zn}_{x}\right)\left(\mathrm{N}_{1-x} \mathrm{O}_{x}\right)$ solid solution catalysis surveys from Asia. Catal Surv Asia 2007;11(4):145-57.

[18] Dare-Edwards MP, Goodenough JB, Hamnett A, Trevellick PR. Electrochemistry and photoelectrochemistry of iron(III) oxide. J Chem Soc Faraday Trans 1 1983;79:2027-41.

[19] Hara M, Waraksa CC, Lean JT, Lewis BA, Mallouk TE. Photocatalytic water oxidation in a buffered Tris(2,2'-bipyridyl) ruthenium complex-colloidal $\mathrm{IrO}_{2}$ system. J Phys Chem A 2000;104(22):5275-80.

[20] Harriman A, Pickering IJ, Thomas JM, Christensen PA. Metal oxides as heterogeneous catalysts for oxygen evolution under photochemical conditions. J Chem Soc Faraday Trans 1 1988;84:2795-806.

[21] Kiwi J, Grätzel M. Oxygen evolution from water via redox catalysis. Angew Chem Int Ed 1978;17(11):860-1.

[22] Kiwi J, Grätzel M. Colloidal redox catalysts for evolution of oxygen and for light-induced evolution of hydrogen from water. Angew Chem Int Ed 1979;18(8):624-6.

[23] Tilley SD, Cornuz M, Sivula K, Grätzel M. Light-induced water splitting with hematite: improved nanostructure and iridium oxide catalysis. Angew Chem Int Ed 2010;49(36):6405-8.

[24] Yokoyama D, Hashiguchi D, Maeda K, Minegishi T, Takata $\mathrm{T}$, Abe R, Kubota J, Domen $\mathrm{K}$. $\mathrm{Ta}_{3} \mathrm{~N}_{5}$ photoanodes for water splitting prepared by sputtering. Thin Solid Films 2011;519(7):2087-92.

[25] Maeda K, Higashi M, Siritanaratkul B, Abe R, Domen K. $\mathrm{SrNbO}_{2} \mathrm{~N}$ as a water-splitting photoanode with a wide visiblelight absorption band. J Am Chem Soc 2011;133(32): 12334-7.

[26] Le Paven-Thivet C, Ishikawa A, Ziani A, Le Gendre L, Yoshida M, Kubota J, Tessier F, Domen K. Photoelectrochemical properties of crystalline perovskite lanthanum titanium oxynitride films under visible light. J Phys Chem C 2009;113(15):6156-62.

[27] Abe R, Higashi M, Domen K. Facile fabrication of an efficient oxynitride $\mathrm{TaON}$ photoanode for overall water splitting into $\mathrm{H}_{2}$ and $\mathrm{O}_{2}$ under visible light irradiation. J Am Chem Soc 2010;132(34):11828-9.

[28] Ishikawa A, Takata T, Kondo JN, Hara M, Kobayahi H, Domen K. Oxysulfide $\mathrm{Sm}_{2} \mathrm{Ti}_{2} \mathrm{~S}_{2} \mathrm{O}_{5}$ as a stable photocatalyst for water oxidation and reduction under visible light irradiation $(\lambda \leq 650$ nm). J Am Chem Soc 2002;124(45):13547-53.

[29] Iwase A, Kato H, Kudo A. A novel photodeposition method in the presence of nitrate ions for loading of an iridium oxide cocatalyst for water splitting. Chem Lett 2005;34(7):946-7.

[30] Youngblood WJ, Lee SHA, Maeda K, Mallouk TE. Visible light water splitting using dye-sensitized oxide semiconductors. 2009;42(12):1966-73.

[31] Maeda K, Xiong A, Yoshinaga T, Ikeda T, Sakamoto N, Hisatomi T, Takashima M, Lu D, Kanehara M, Setoyama T, Teranishi T, Domen K. Photocatalytic overall water splitting promoted by two different cocatalysts for hydrogen and oxygen evolution under visible light. Angew Chem Int Ed 2010;49(24):4096-9.

[32] Ye H, Park HS, Bard AJ. Screening of electrocatalysts for photoelectrochemical water oxidation on $\mathrm{W}$-doped $\mathrm{BiVO}_{4}$ photocatalysts by scanning electrochemical microscopy. J Phys Chem C 2011;115(25):12464-70.
[33] Corrigan DA. The catalysis of the oxygen evolution reaction by iron impurities in thin film nickel oxide electrodes. J Electrochem Soc 1987;134(2):377-84.

[34] Merrill MD, Dougherty RC. Metal oxide catalysts for the evolution of $\mathrm{O}_{2}$ from $\mathrm{H}_{2} \mathrm{O}$. J Phys Chem C 2008;112(10): 3655-66.

[35] Miller EL, Rocheleau RE. Electrochemical behavior of reactively sputtered iron-doped nickel oxide. J Electrochem Soc 1997;144(9):3072-7.

[36] Corrigan DA, Conell RS, Fierro CA, Scherson DA. In-situ moessbauer study of redox processes in a composite hydroxide of iron and nickel. J Phys Chem 1987;91(19):5009-11.

[37] Kleiman-Shwarsctein A, Hu YS, Stucky GD, McFarland EW. $\mathrm{NiFe}$-oxide electrocatalysts for the oxygen evolution reaction on Ti doped hematite photoelectrodes. Electrochem Commun 2009;11(6):1150-3.

[38] Hong YR, Liu Z, Al-Bukhari SFBSA, Lee CJJ, Yung DL, Chi D, Hor TSA. Effect of oxygen evolution catalysts on hematite nanorods for solar water oxidation. Chem Commun 2011;47:10653-5.

[39] McEvoy JP, Gascon JA, Batista VS, Brudvig GW. The mechanism of photosynthetic water splitting. Photochem Photobiol Sci 2005;4:940-9.

[40] Dau H, Haumann M. Considerations on the mechanism of photosynthetic water oxidation - dual role of oxo-bridges between $\mathrm{Mn}$ ions in (i) redox-potential maintenance and (ii) proton abstraction from substrate water. Photosynth Res 2005;84(1-3):325-31.

[41] Hocking RK, Brimblecombe R, Chang LY, Singh A, Cheah MH, Glover C, Casey WH, Spiccia L. Water-oxidation catalysis by manganese in a geochemical-like cycle. Nature Chem 2011;3:461-6.

[42] Kanan MW, Nocera DG. In situ formation of an oxygenevolving catalyst in neutral water containing phosphate and $\mathrm{Co}^{2+}$. Science 2008;321(5892):1072-5.

[43] Schrebler RS, Ballesteros L, Burgos A, Muñoz EC, Grez P, Leinen D, Martín F, Ramos-Barrado JR, Dalchiele EA. Electrodeposited nanostructured $\alpha-\mathrm{Fe}_{2} \mathrm{O}_{3}$ photoanodes for solar water splitting: effect of surface co-modification on photoelectrochemical performance. J Electrochem Soc 2011;158(8):D500-5.

[44] Kay A, Cesar I, Grätzel M. New benchmark for water photooxidation by nanostructured $\alpha-\mathrm{Fe}_{2} \mathrm{O}_{3}$ films. J Am Chem Soc 2006;128(49):15714-21.

[45] Steinmiller EMP, Choi KS. Photochemical deposition of cobaltbased oxygen evolving catalyst on a semiconductor photoanode for solar oxygen production. PNAS 2009;106(49):20633-6.

[46] Zhong DK, Sun J, Inumaru H, Gamelin DR. Solar water oxidation by composite catalyst $/ \alpha-\mathrm{Fe}_{2} \mathrm{O}_{3}$ photoanodes. J Am Chem Soc 2009;131(17):6086-7.

[47] Barroso M, Cowan AJ, Pendlebury SR, Grätzel M, Klug DR, Durrant JR. The role of cobalt phosphate in enhancing the photocatalytic activity of $\alpha-\mathrm{Fe}_{2} \mathrm{O}_{3}$ toward water oxidation. J Am Chem Soc 2011;133:14868-71.

[48] Zhong DK, Cornuz M, Sivula K, Grätzel M, Gamelin DR. Photo-assisted electrodeposition of cobalt-phosphate (Co-Pi) catalyst on hematite photoanodes for solar water oxidation. Energy Environ Sci 2011;4:1759-64.

[49] Seabold JA, Choi KS. Effect of a cobalt-based oxygen evolution catalyst on the stability and the selectivity of photo-oxidation reactions of a $\mathrm{WO}_{3}$ photoanode. Chem Mater 2011;23(5):1105-12.

[50] Zhong DK, Choi S, Gamelin DR. Near-complete suppression of surface recombination in solar photoelectrolysis by "Co-Pi" catalyst-modified W:BiVO ${ }_{4}$. J Am Chem Soc 2011;133(145):18370-7. 
[51] Jeon TH, Choi W, Park H. Cobalt-phosphate complexes catalyze the photoelectrochemical water oxidation of $\mathrm{BiVO}_{4}$ electrodes. Phys Chem Chem Phys 2011;13:21392-401.

[52] Pilli SK, Furtak TE, Brown LD, Deutsch TG, Turner JA, Herring AM. Cobalt-phosphate (Co-Pi) catalyst modified Mo-doped $\mathrm{BiVO}_{4}$ photoelectrodes for solar water oxidation. Energy Environ Sci 2011;4:5028-34.

[53] Young ER, Costi R, Paydavosi S, Nocera DG, Bulović V. Photoassisted water oxidation with cobalt-based catalyst formed from thin-film cobalt metal on silicon photoanodes. Energy Environ Sci 2011;4:2058-61.

[54] Pijpers JJH, Winkler MT, Surendranath Y, Buonassisi T, Nocera DG. Light-induced water oxidation at silicon electrodes functionalized with a cobalt oxygen-evolving catalyst. PNAS 2011;108(25):10056-61.

[55] Zhong DK, Gamelin DR. Photoelectrochemical water oxidation by cobalt catalyst ("Co-Pi")/ $\alpha-\mathrm{Fe}_{2} \mathrm{O}_{3}$ composite photoanodes: oxygen evolution and resolution of a kinetic bottleneck. J Am Chem Soc 2010;132(12):4202-7.

[56] Reece SY, Hamel JA, Sung K, Jarvi TD, Esswein AJ, Pijpers JJH, Nocera DG. Wireless solar water splitting using siliconbased semiconductors and earth-abundant catalysts. Science 2011;334(6056):645-8.

[57] Kronawitter CX, Vayssieres L, Shen S, Guo L, Wheeler DA, Zhang JZ, Antoun BR, Mao SS. A perspective on solar-driven water splitting with all-oxide hetero-nanostructures. Energy Environ Sci 2011;4:3889-99.

[58] Grätzel M. Review article: Photoelectrochemical cells. Nature 2001;414:338-44.

[59] Kronawitter CX, Bakke JR, Wheeler DA, Wang WC, Chang C, Antoun BR, Zhang JZ, Guo J, Bent SF, Mao SS, Vayssieres L. Electron enrichment in $3 \mathrm{~d}$ transition metal oxide hetero-nanostructures. Nano Lett 2011;11(9):3855-61.

[60] Smith W, Wolcott A, Fitzmorris RC, Zhang JZ, Zhao Y. Quasicore-shell $\mathrm{TiO}_{2} / \mathrm{WO}_{3}$ and $\mathrm{WO}_{3} / \mathrm{TiO}_{2}$ nanorod arrays fabricated by glancing angle deposition for solar water splitting. J Mater Chem 2011;21:10792-800.

[61] Kronawitter CX, Ma Z, Liu D, Mao SS, Antoun BR. Engineering impurity distributions in photoelectrodes for solar water oxidation. Adv Energy Mater 2012;2(1):52-7.

[62] Diamant Y, Chappel S, Chen SG, Melamed O, Zaban A. Coreshell nanoporous electrode for dye sensitized solar cells: the effect of shell characteristics on the electronic properties of the electrode. Coord Chem Rev 2004;248(13-14):1271-6.

[63] O'Regan BC, Scully S, Mayer AC, Palomares E, Durrant J. The effect of $\mathrm{Al}_{2} \mathrm{O}_{3}$ Barrier Layers in $\mathrm{TiO}_{2} /$ Dye/CuSCN photovoltaic cells explored by recombination and DOS characterization using transient photovoltage measurements. J Phys Chem B 2005;109(10):4616-23.

[64] Bae ST, Shin H, Kim JY, Jung HS, Hong KS. Roles of MgO coating layer on mesoporous $\mathrm{TiO}_{2} /$ ITO electrode in a photoelectrochemical cell for water splitting. J Phys Chem C 2008; 112(26):9937-42.

[65] Guo L, Hung D, Wang W, Shen W, Zhu L, Chien CL, Searson PC. Tunnel barrier photoelectrodes for solar water splitting. Appl Phys Lett 2010;97:063111.

[66] Le Formal F, Tétreault N, Cornuz M, Moehl T, Grätzel M, Sivula K. Passivating surface states on water splitting hematite photoanodes with alumina overlayers. Chem Sci 2011;2:737-43.

[67] Hisatomi T, Le Formal F, Cornuz M, Brillet J, Tétreault N, Sivula K, Grätzel M. Cathodic shift in onset potential of solar oxygen evolution on hematite by 13-group oxide overlayers. Energy Environ Sci 2011;4:2512-5.
[68] Leroy CM, Maegli AE, Sivula K, Hisatomi T, Xanthopoulos N, Otal EH, Yoon S, Weidenkaff A, Sanjines R, Grätzel M. $\mathrm{LaTiO}_{2} \mathrm{~N} / \mathrm{In}_{2} \mathrm{O}_{3}$ photoanodes with improved performance for solar water splitting. Chem Commun 2012;48:820-2.

[69] Awazu K, Fujimaki M, Rockstuhl C, Tominaga J, Murakami H, Ohki Y, Yoshida N, Watanabe T. A plasmonic photocatalyst consisting of silver nanoparticles embedded in titanium dioxide. J Am Chem Soc 2008;130(5):1676-80.

[70] Wang P, Huang BB, Qin XY, Zhang XY, Dai Y, Wei JY, Whangbo MH. Ag@ AgCl: A highly efficient and stable photocatalyst active under visible light. Angew Chem Int Ed 2008;47(41):7931-3.

[71] Qu Y, Cheng R, Su Q, Duan X. Plasmonic enhancements of photocatalytic activity of $\mathrm{Pt} / \mathrm{n}-\mathrm{Si} / \mathrm{Ag}$ photodiodes using $\mathrm{Au} / \mathrm{Ag}$ Core/Shell Nanorods. J Am Chem Soc 2011;133(42):16730-3.

[72] Zhou X, Hu C, Hu X, Peng T, Qu J. Plasmon-assisted degradation of toxic pollutants with $\mathrm{Ag}-\mathrm{AgBr} / \mathrm{Al}_{2} \mathrm{O}_{3}$ under visible-light irradiation. J Phys Chem C 2010;114(6):2746-50.

[73] Zhu M, Chen P, Liu M. Graphene oxide enwrapped Ag/AgX $(\mathrm{X}=\mathrm{Br}, \mathrm{Cl})$ nanocomposite as a highly efficient visible-light plasmonic photocatalyst. ACS Nano 2011;5(6):4529-36.

[74] Christopher P, Ingram DB, Linic S. Enhancing photochemical activity of semiconductor nanoparticles with optically active $\mathrm{Ag}$ nanostructures: photochemistry mediated by Ag surface plasmons. J Phys Chem C 2010;114(19):9173-7.

[75] Hou W, Hung WH, Pavaskar P, Goeppert A, Aykol M, Cronin SB. Photocatalytic conversion of $\mathrm{CO}_{2}$ to hydrocarbon fuels via plasmon-enhanced absorption and metallic interband transitions. ACS Catal 2011;1(8);929-36.

[76] Kowalska E, Abe R, Ohtani B. Visible light-induced photocatalytic reaction of gold-modified titanium(IV) oxide particles: action spectrum analysis. Chem Commun 2009;2:241-3.

[77] Kowalska E, Mahaney OOP, Abe R, Ohtania B. Visiblelight-induced photolysis through surface plasmon excitation of gold on titania surfaces. Phys Chem Chem Phys 2010;12: 2344-55.

[78] Wu T, Liu S, Luo Y, Lu W, Wang L, Sun X. Surface plasmon resonance-induced visible light photocatalytic reduction of graphene oxide: Using Ag nanoparticles as a plasmonic photocatalyst. Nanoscale 2011;3:2142-4.

[79] Zhai W, Xue S, Zhu A, Luo Y, Tian Y. Plasmon-driven selective oxidation of aromatic alcohols to aldehydes in water with recyclable $\mathrm{Pt} / \mathrm{TiO}_{2}$ nanocomposites. Chem Cat Chem 2011;3(1):127-30.

[80] Abdulla-Al-Mamun Md, Kusumoto Y, Zannat T, Islam MdS. Synergistic cell-killing by photocatalytic and plasmonic photothermal effects of $\mathrm{Ag} @ \mathrm{TiO}_{2}$ core-shell composite nanoclusters against human epithelial carcinoma (HeLa) cells. Appl Catal A Gen 2011;398(1-2):134-42.

[81] Linic S, Christopher P, Ingram DB. Plasmonic-metal nanostructures for efficient conversion of solar to chemical energy. Nature Mater 2011;10:911-21.

[82] Warren SC, Thimsen E. Plasmonic solar water splitting. Energy Environ Sci 2012;5:5133-46.

[83] Hartland GV. Optical studies of dynamics in noble metal nanostructures. Chem Rev 2011;111(6):3858-87.

[84] Halas NJ, Lal S, Chang WS, Link S, Nordlander P. Plasmons in strongly coupled metallic nanostructures. Chem Rev 2011;111(6):3913-61.

[85] Atwater HA, Polman A. Plasmonics for improved photovoltaic devices. Nat Mater 2010;9:205-13.

[86] Schuller JA, Barnard ES, Cai W, Jun YC, White JS, Brongersma ML. Plasmonics for extreme light concentration and manipulation. Nat Mater 2010;9:193-204. 
[87] Hou W, Liu Z, Pavaskar P, Hung WH, Cronin SB. Plasmonic enhancement of photocatalytic decomposition of methyl orange under visible light. J Catal 2011;277(2):149-53.

[88] Primo A, Corma A, García H. Titania supported gold nanoparticles as photocatalyst. Phys Chem Chem Phys 2011;13: 886-910.

[89] Zhang Q, Lima DQ, Lee I, Zaera F, Chi M, Yin Y. A highly active titanium dioxide based visible-light photocatalyst with nonmetal doping and plasmonic metal decoration. Angew Chem Int Ed 2011;50(31):7088-92.

[90] Tian Y, Tatsuma T. Mechanisms and applications of plasmoninduced charge separation at $\mathrm{TiO}_{2}$ films loaded with gold nanoparticles. Am Chem Soc 2005;127(20):7632-7.

[91] Chen JJ, Wu JCS, Wu PC, Tsai DP. Plasmonic photocatalyst for $\mathrm{H}_{2}$ evolution in photocatalytic water splitting. J Phys Chem C 2011;115(1):210-6.

[92] Liu Z, Hou W, Pavaskar P, Aykol M, Cronin SB. Plasmon resonant enhancement of photocatalytic water splitting under visible illumination. Nano Lett 2011;11(3):1111-6.

[93] Yuzawa H, Yoshida T, Yoshida H. Gold nanoparticles on titanium oxide effective for photocatalytic hydrogen formation under visible light. Appl Catal B 2012;115-116:294-302.

[94] Silva CG, Juárez R, Marino T, Molinari R, García H. Influence of excitation wavelength (UV or visible light) on the photocatalytic activity of titania containing gold nanoparticles for the generation of hydrogen or oxygen from water. J Am Chem Soc 2011;133(3):595-602.

[95] Yu J, Dai G, Huang B. Fabrication and characterization of visible-light-driven plasmonic photocatalyst $\mathrm{Ag} / \mathrm{AgCl} / \mathrm{TiO}_{2}$ nanotube arrays. J Phys Chem C 2009;113(37):16394-401.

[96] Tian Y, Tatsuma T. Plasmon-induced photoelectrochemistry at metal nanoparticles supported on nanoporous $\mathrm{TiO}_{2}$. Chem Commun 2004;16:1810-1.

[97] Chuang HY, Chen DH. Fabrication and photoelectrochemical study of $\mathrm{Ag} @ \mathrm{TiO}_{2}$ nanoparticle thin film electrode. Int J Hydrogen Energy 2011;36(16):9487-95.

[98] Ingram DB, Linic S. Water splitting on composite plasmonicmetal/semiconductor photoelectrodes: evidence for selective plasmon-induced formation of charge carriers near the semiconductor surface. J Am Chem Soc 2011;133(14):5202-5.

[99] Thimsen E, Le Formal F, Grätzel M, Warren SC. Influence of plasmonic Au nanoparticles on the photoactivity of $\mathrm{Fe}_{2} \mathrm{O}_{3}$ electrodes for water splitting. Nano Lett 2011;11(1):35-43.

[100] Thomann I, Pinaud BA, Chen Z, Clemens BM, Jaramillo TF, Brongersma ML. Plasmon enhanced solar-to-fuel energy conversion. Nano Lett 2011;11:3440-6.

[101] Primo A, Marino T, Corma A, Molinari R, García H. Efficient visible-light photocatalytic water splitting by minute amounts of gold supported on nanoparticulate $\mathrm{CeO}_{2}$ obtained by a biopolymer templating method. J Am Chem Soc 2011;133(18):6930-3.

[102] Kudo A. Z-scheme photocatalyst systems for water splitting under visible light irradiation. MRS Bull 2011;36:32-8.

[103] Sasakia Y, Iwasea A, Katoa H, Kudo A. The effect of cocatalyst for Z-scheme photocatalysis systems with an $\mathrm{Fe}^{3+} / \mathrm{Fe}^{2+}$ electron mediator on overall water splitting under visible light irradiation. J Catal 2008;259(1):133-7.

[104] Tada H, Mitsui T, Kiyonaga T, Akita T, Tanaka K. All-solidstate $\mathrm{Z}$-scheme in $\mathrm{CdS}-\mathrm{Au}-\mathrm{TiO}_{2}$ three-component nanojunction system. Nature Mater 2006;5:782-6.

[105] Zhang LS, Wong KH, Chen ZG, Yu JC, Zhao JC, Hu C, Chan $\mathrm{CY}$, Wong PK. AgBr-Ag- $\mathrm{Bi}_{2} \mathrm{WO}_{6}$ nanojunction system: a novel and efficient photocatalyst with double visible-light active components. Appl Catal A 2009;363(1-2):221-9.
[106] Hu C, Lan YQ, Qu JH, Hu XX, Wang AM. Ag/AgBr/TiO, visible light photocatalyst for destruction of azodyes and bacteria. J Phys Chem B 2006;110(9):4066-72.

[107] Wang X, Li S, Ma Y, Yu H, Yu J. $\mathrm{H}_{2} \mathrm{WO}_{4} \cdot \mathrm{H}_{2} \mathrm{O} / \mathrm{Ag} / \mathrm{AgCl}$ composite nanoplates: a plasmonic $\mathrm{z}$-scheme visible-light photocatalyst. J Phys Chem C 2011;115(30):14648-55.

[108] Wang X, Liu G, Lu GQ, Cheng HM. Stable photocatalytic hydrogen evolution from water over $\mathrm{ZnO}-\mathrm{CdS}$ core-shell nanorods. Int J Hydrogen Energy 2010;35(15):8199-205.

[109] Wang X, Liu G, Chen ZG, Li F, Wang L, Lu GQ, Cheng HM. Enhanced photocatalytic hydrogen evolution by prolonging the lifetime of carriers in $\mathrm{ZnO} / \mathrm{CdS}$ heterostructures. Chem Commun 2009;23:3452-4.

[110] Wang X, Liu G, Wang L, Chen ZG, Lu GQM, Cheng HM. ZnO-CdS@Cd heterostructure for effective photocatalytic hydrogen generation. Adv Energy Mater 2012;2(1):42-6.

[111] Wang X, Liu G, Wang L, Pan J, Lu GQM, Cheng HM. TiO films with oriented anatase $\{001\}$ facets and their photoelectrochemical behavior as CdS nanoparticle sensitized photoanodes. J Mater Chem 2011;21:869-73.

[112] Yun HJ, Lee H, Kim ND, Lee DM, Yu S, Yi J. A combination of two visible-light responsive photocatalysts for achieving the Z-scheme in the solid state. ACS Nano 2011;5(5):4084-90.

[113] Fu N, Jin Z, Wu Y, Lu G, Li D. Z-Scheme photocatalytic system utilizing separate reaction centers by directional movement of electrons. J Phys Chem C 2011;115(17):8586-93.

[114] Sasaki Y, Nemoto H, Saito K, Kudo A. Solar water splitting using powdered photocatalysts driven by Z-schematic interparticle electron transfer without an electron mediator. J Phys Chem C 2009;113(40):17536-42.

[115] Iwase A, Ng YH, Ishiguro Y, Kudo A, Amal R. Reduced graphene oxide as a solid-state electron mediator in $\mathrm{z}$-scheme photocatalytic water splitting under visible light. J Am Chem Soc 2011;133(29):11054-7.

[116] Arpin KA, Mihi A, Johnson HT, Baca AJ, Rogers JA, Lewis JA, Braun PV. Multidimensional architectures for functional optical devices. Adv Mater 2010;22(10):1084-101.

[117] Nishimura S, Abrams N, Lewis BA, Halaoui LI, Mallouk TE, Benkstein KD, van de Lagemaat J, Frank AJ. Standing wave enhancement of red absorbance and photocurrent in dyesensitized titanium dioxide photoelectrodes coupled to photonic crystals. J Am Chem Soc 2003;125:6306-10.

[118] Halaoui LI, Abrams NM, Mallouk TE. Increasing the conversion efficiency of dye-sensitized $\mathrm{TiO}_{2}$ photoelectrochemical cells by coupling to photonic crystals. J Phys Chem B 2005;109(13):6334-42.

[119] Lee SHA, Abrams NM, Hoerz PG, Barber GD, Halaoui LI, Mallouk TE. Coupling of titania inverse opals to nanocrystalline titania layers in dye-sensitized solar cells. J Phys Chem B 2008;112(46):14415-21.

[120] Kwak ES, Lee W, Park NG, Kim J, Lee H. Compact inverseopal electrode using non-aggregated $\mathrm{TiO}_{2}$ nanoparticles for dyesensitized solar cells. Adv Funct Mater 2009;19(7):1093-9.

[121] Guldin S, Hüttner S, Kolle M, Welland ME, Müller-Buschbaum P, Friend RH, Steiner U, Tütreault N. Dye-sensitized solar cell based on a three-dimensional photonic crystal. Nano Lett 2010;10(7):2303-9.

[122] Chen JIL, Von Freymann F, Choi SY, Kitaev V, Ozin AG. Amplified photochemistry with slow photons. Adv Mater 2006;18(14):1915-9.

[123] Chen JIL, Von Freymann F, Kitaev V, Ozin GA. Effect of disorder on the optically amplified photocatalytic efficiency of titania inverse opals. J Am Chem Soc 2007;129(5):1196-202. 
[124] Chen JIL, Loso E, Ebrahim N, Ozin GA. Synergy of slow photon and chemically amplified photochemistry in platinum nanocluster-loaded inverse titania opals. J Am Chem Soc 2008;130(16):5420-1.

[125] Li Q, Shang JK. Inverse opal structure of nitrogen-doped titanium oxide with enhanced visible-light photocatalytic activity. J Am Ceram Soc 2008;91(2):660-3.

[126] Xu J, Yang B, Wu M, Fu Z, Lv Y, Zhao Y. Novel N-F-codoped $\mathrm{TiO}_{2}$ inverse opal with a hierarchical meso-/macroporous structure: synthesis, characterization, and photocatalysis. J Phys Chem C 2010;114(36):15251-9.

[127] Li Y, Kunitake T, Fujikawa S. Efficient fabrication and enhanced photocatalytic activities of $3 \mathrm{~d}$-ordered films of titania hollow spheres. J Phys Chem B 2006;110(26):13000-4.

[128] Lee SH, Teshima K, Fujisawa M, Fujii S, Endod M, Oishi S. Fabrication of highly ordered, macroporous $\mathrm{Na}_{2} \mathrm{~W}_{4} \mathrm{O}_{13}$ arrays by spray pyrolysis using polystyrene colloidal crystals as templates. Phys Chem Chem Phys 2009;11:3628-33.

[129] Cai Z, Teng J, Xiong Z, Li Y, Li Q, Lu X, Zhao XS. Fabrication of $\mathrm{TiO}_{2}$ binary inverse opals without overlayers via the sandwich-vacuum infiltration of precursor. Langmuir 2011;27(8):5157-64.

[130] Ma TY, Zhang XJ, Shao GS, Cao JL, Yuan ZY. Ordered macroporous titanium phosphonate materials: synthesis, photocatalytic activity, and heavy metal ion adsorption. J Phys Chem C 2008;112(8):3090-6.

[131] Sordello F, Duca C, Maurino V, Minero C. Photocatalytic metamaterials: $\mathrm{TiO}_{2}$ inverse opals. Chem Commun 2011;47: 6147-9.

[132] Liu J, Liu G, Li M, Shen W, Liu Z, Wang J, Zhao J, Jiang L, Song Y. Enhancement of photochemical hydrogen evolution over Pt-loaded hierarchical titania photonic crystal. Energy Environ Sci 2010;3:1503-6.

[133] Cheng C, Karuturi SK, Liu L, Liu J, Li H, Su LT, Tok AIY, Fan HJ. Quantum-dot-sensitized $\mathrm{TiO}_{2}$ inverse opals for photoelectrochemical hydrogen generation. Small 2012;8(1): 37-42.

[134] El Harakeh M, Halaoui L. Enhanced conversion of light at $\mathrm{TiO}_{2}$ photonic crystals to the blue of a stop band and at $\mathrm{TiO}_{2}$ random films sensitized with Q-CdS: order and disorder. J Phys Chem C 2010;114(6):2806-13.

[135] Chen X, Li Z, Ye J, Zou Z. Forced impregnation approach to fabrication of large-area, three-dimensionally ordered macroporous metal oxides. Chem Mater 2010;22(12):3583-5.

[136] Chen X, Ye J, Ouyang S, Kako T, Li Z, Zou Z. Enhanced incident photon-to-electron conversion efficiency of tungsten trioxide photoanodes based on 3d-photonic crystal design. ACS Nano 2011;5(6):4310-8.
[137] Zhang L, Baumanis C, Robben L, Kandiel T, Bahnemann D. $\mathrm{Bi}_{2} \mathrm{WO}_{6}$ inverse opals: facile fabrication and efficient visiblelight-driven photocatalytic and photoelectrochemical watersplitting activity. Small 2011;7(19):2714-20.

[138] Liu S, Will G, Martens W, Bell S. Photocatalytic Hydrogen Production and Water Purification with Iron Oxide under UV/ Vis Irradiation, 17th World Hydrogen Energy Conference, Brisbane, Australia, 15-19 June 2008.

[139] O'Brien PG, Puzzo DP, Chutinan A, Bonifacio LD, Ozin GA, Kherani NP. Selectively transparent and conducting photonic crystals. Adv Mater 2010;22(5):611-6.

[140] Fan Z, Ruebusch DJ, Rathore AA, Kapadia R, Ergen O, Leu PW, Javey A. Challenges and prospects of nanopillar-based solar cells. Nano Res 2009;2(11):829-43.

[141] Martinson ABF, Elam JW, Liu J, Pellin MJ, Marks TJ, Hupp JT. Radial electron collection in dye-sensitized solar cells. Nano Lett 2008;8(9):2862-6.

[142] Arsenault E, Soheilnia N, Ozin GA. Periodic macroporous nanocrystalline antimony-doped tin oxide electrode. ACS Nano 2011;5(4):2984-8.

[143] Yang Z, Gao S, Li W, Vlasko-Vlasov V, Welp U, Kwok WK, $\mathrm{Xu} \mathrm{T}$. Three-dimensional photonic crystal fluorinated Tin oxide (FTO) electrodes: synthesis and optical and electrical properties. ACS Appl Mater Interfaces 2011;3(4):1101-8.

[144] Yan H, Yang J, Ma G, Wu G, Zong X, Lei Z, Shi J, Li C. Visible-light-driven hydrogen production with extremely high quantum efficiency on Pt-PdS/CdS photocatalyst. J Catal 2009;266(2):165-8.

[145] Liu M, Wang L, Lu GM, Yao X, Guo L. Twins in $\mathrm{Cd}_{1-x} \mathrm{Zn}_{\mathrm{x}} \mathrm{S}$ solid solution: Highly efficient photocatalyst for hydrogen generation from water. Energy Environ Sci 2011;4:1372-8.

[146] Maeda K, Teramura K, Domen K. Effect of post-calcination on photocatalytic activity of $\left(\mathrm{Ga}_{1-\mathrm{Zn}} \mathrm{Zn}_{2}\left(\mathrm{~N}_{1-\mathrm{O}} \mathrm{O}\right)\right.$ solid solution for overall water splitting under visible light. J Catal 2008;254(2):198-204.

[147] Khaselev O, Turner JA. A monolithic photovoltaicphotoelectrochemical device for hydrogen production via water splitting. Science 1998;280:425-7.

[148] Paracchino A, Laporte V, Sivula K, Grätzel M, Thimsen E. Highly active oxide photocathode for photoelectrochemical water reduction. Nat Mater 2011;10:456-61.

[149] Miller EL, Gaillard N, Kaneshiro J, DeAngelis A, Garland R. Progress in new semiconductor materials classes for solar photoelectrolysis. Int J Energy Res 2010;34(14):1215-22.

Received February 28, 2012; accepted March 28, 2012 